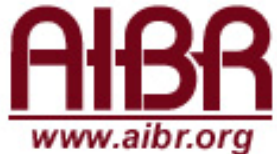

REVISTA DE ANTROPOLOGÍA IBEROAMERICANA

ESTIMADO LECTORIA:

GRACIAS POR DESCARGAR ESTE ARTÍCULO. EL TEXTO QUE ESTÁ A PUNTO DE CONSULTAR ES DE ACCESO LIBRE Y GRATUITO GRACIAS AL TRABAJO Y LA COLABORACIÓN DESINTERESADA DE UN AMPLIO COLECTIVO DE PROFESIONALES.

USTED PUEDE AYUDARNOS A INCREMENTAR LA CALIDAD Y A MANTENER LA LIBRE DIFUSIÓN DE LOS CONTENIDOS DE ESTA REVISTA A TRAVÉS DE SU AFILIACIÓN A LA ASOCIACIÓN AIBR:

http://www.aibr.org/antropologia/aibr/socios.php

La afiliación a AIBR tiene un coste mínimo al año, y le proporcionará las siguientes ventajas y privilegios:

1. Recibir en su domicilio la revista impresa, en Europa y América (tres números anuales), así como todas las novedades relativas al funcionamiento de la asociación

2. Recibir en su domicilio, a precio especial o de forma gratuita, cuantas publicaciones adicionales edite la asociación.

3. Derecho a voto en las asambleas de socios, así como a presentarse como candidato a la elección de su Junta Directiva.

4. Recibir el boletín de socios (tres números anuales), así como la información económica relativa a cuentas anuales de la asociación.

5. Beneficiarse de las reducciones de precio en congresos, cursos, libros y todos aquellos convenios a los que a nivel corporativo AIBR llegue con otras entidades. En este momento, existen los siguientes acuerdos:

o Reducción de un $20 \%$ en el precio de todos los libros publicados por la editorial MELUSINA.

o Reducción de un $20 \%$ en el precio de todos los libros publicados por la editorial SEPHA.

o Reducción de un 30\% en el precio de todos los libros publicados por la editorial GRAN VÍA.

o Derecho a cuota reducida en los congresos trianuales de la FAAEE (España) y a los bianuales de la Sociedad Española de Antropología Aplicada.

o Derecho a cuota reducida en los congresos la IUAES.

6. Promoción gratuita, tanto a través de la revista electrónica como de la revista impresa, de aquellas publicaciones de las que sea autor y que estén registradas con ISBN. La difusión se realiza entre más de 5.200 antropólogos suscritos a la revista.

7. Cuenta de correo electrónico ilimitada de la forma socio@aibr.org, para consultar a través de webmail o cualquier programa externo.

8. Espacio para web personal de la forma http://www.aibr.org/(directorio)/(nombre) y cuenta propia de ftp.

9. Acceso con clave a todos los documentos de la Intranet de socios de AIBR, incluida la consulta a artículos en proceso de evaluación de la revista AIBR.

10. Promoción gratuita a través de la revista (banner rotativo y reseña) de aquellos eventos, congresos, conferencias o cursos en los que usted forme parte del comité organizador.

11. Opción a formar parte como evaluador de los artículos recibidos por la revista.

IMPORTE DE LA CUOTA ANUAL: Hasta diciembre de 2008, la cuota única anual es de 32 (euros). Su validez es de un año a partir del pago de la cuota. Por favor, revise la actualización de cuotas en nuestra web.

PARA HACERSE SOCIO DE AIBR, POR FAVOR, CONSULTE LA SIGUIENTE DIRECCIÓN:

http://www.aibr.org/antropologia/aibr/socios.php 


\title{
e.8 antropología Y MEdio AMBIENTE. REVISIÓN DE UNA TRADICIÓN Y NUEVAS PERSPECTIVAS DE ANÁLISIS EN LA PROBLEMÁTICA ECOLÓGICA
}

\section{Beatriz Santamarina Campos}

Universidad de Valencia

Recibido: 26 de febrero de 2008

Aceptado: 8 de abril de 2008

\begin{abstract}
Resumen
Durante los últimos años la producción etnográfica sobre el conflicto medio ambiental ha generado un volumen considerable de aportaciones. En este artículo se contextualiza, en la tradición antropológica, las distintas perspectivas (la ecológica, la simbólica cognitiva y la política) que se han ocupado del entorno, de la construcción de la naturaleza y del papel otorgado a la naturaleza en la distribución de relaciones de poder. Todo para situar a las perspectivas de la ecología simbólica y ecología política como los enfoques, desde nuestro punto de vista, más pertinentes para abordar el conflicto medio ambiental. En un mundo donde se imponen visiones hegemónicas y discursos ecológicos globalizados, basados en una racionalidad político-económica que se pretende única, se hace necesario un análisis crítico para descifrar las claves de nuestra práctica cultural y para poner en práctica todo el conocimiento local aprendido, que permita sacar a la luz otros discursos practicables posibles desde lógicas marginales.
\end{abstract}

\section{Palabras claves}

Ecología cultural, Ecología simbólica, ecología política, antropología medio ambiental

\section{ANTHROPOLOGY AND THE ENVIRONMENT. REVISION OF A TRADITION AND NEW ANALYTICAL PERSPECTIVES FOR THE ECOLOGICAL PROBLEM}

\begin{abstract}
In recent years, ethnographic work on environmental conflict has generated a considerable amount of activity. This article contextualizes the different perspectives (ecological, symboliccognitive and political) that have dealt with the environment, the construction of nature, and the role given to nature in the distribution of power relations. The authors consider the perspectives of symbolic ecology and political ecology to be the approaches that are most relevant for addressing environmental conflict. In a world of imposed hegemonic visions and globalized ecological discourses based on a political-economic rationality that claims to be unique, a critical analysis is needed to decipher the code of our practice of culture and to put into practice all of the acquired local knowledge, which will allow us to draw out other possible, viable discourses from marginal logics.
\end{abstract}


Key words

Cultural Ecology, Political Ecology, Symbolic Ecology, Environmental Anthropology

\section{Introducción}

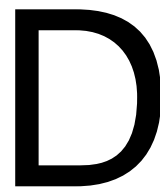

esde la antropología, hacer una aproximación reflexiva al medio ambiente en nuestra práctica cultural supone invitar a la consideración de un tema que ha ocupado un importante volumen en la producción etnográfica. El medio ambiente se presenta como una recapacitación entre dos polos tensionales tan clásicos en la antropología como en nuestra sociedad: naturaleza-cultura. Nos es imposible pensar el medio ambiente sin una referencia explícita a la Naturaleza, y con ella se abre una reflexión sobre lo nuestro. Ahora bien, el fenómeno medioambiental y la necesidad de abordarlo desde una visión concreta, exige una primera mirada sobre cómo la antropología ha contribuido no sólo a la comprensión de nuestras relaciones con la naturaleza, sino también a configurar el mundo de lo natural. Dicha reflexión debe hacerse en dos sentidos. En primer lugar, podemos observar cómo la naturaleza ha sido un eje de vital importancia en el desarrollo de la disciplina antropológica, apareciendo como un polo fundamental en su constitución y distribución de sentidos. Así, una aportación indiscutible de la antropología ${ }^{1}$ es haber definido la cultura frente a la naturaleza; de hecho "la relación entre cultura y naturaleza (o entre población y entorno, si prefiere utilizarse el vocabulario ecológico-técnico) ha ocupado una parte sustancial del análisis antropológico" (Comas d'Argemir, 1998:124). En este sentido, hasta la segunda mitad del siglo XX, la delimitación de la cultura era "negativa porque hablar de cultura equivalía a hacer algún tipo de referencia, implícita o explícitamente, a lo que se estimaba su contrapartida, la naturaleza" (Luque Baena, 1990:93). Después de este largo periodo, asistimos a un reconocimiento de la complejidad y del dinamismo para explicar ambos conceptos, pero las fronteras y las relaciones entre ambos vendrán marcadas, de igual modo, por la delimitación de esferas. Hay que esperar hasta mediados de los 80, con la aparición y el desarrollo de la ecología simbólica, la ecología política y la antropología de la ciencia, para asistir a la superación de esta dicotomía clásica. Sin duda, la reflexión sobre el medio ambiente,

\footnotetext{
${ }^{1}$ Una característica que no es propia de la disciplina porque, como veremos más adelante, la constitución moderna de la ciencia occidental se basa en la distinción ontológica entre mundo natural y mundo social (Latour, 1993).
} 
en un contexto marcado por la globalización y la reestructuración del capitalismo y caracterizado por la destrucción/degradación del entorno, ha contribuido a una redefinición del problema.

Y, en segundo lugar, este papel central ha posibilitado una atención especial a la construcción social del mundo de lo 'natural'. Así, nos interesa atender a las contribuciones que desde la disciplina antropológica ayudan a descubrir la complejidad y las múltiples dimensiones del complejo cultural 'naturaleza'. Las diferentes tradiciones en antropología han abordado la 'naturaleza' de distinta manera: como proceso evolutivo en continuo, como esfera delimitada y contrapuesta, como sistema de flujos..., y en este artículo pretendemos acercarnos a ellas. No obstante, el objetivo no es hacer una síntesis exhaustiva sobre el papel otorgado por los antropólogos a la naturaleza, sino más bien poner al descubierto la importancia y la centralidad que dicha categoría ha ocupado y la pertinencia hoy en día de reflexionar sobre este legado.

En definitiva, en este texto, atenderemos, a las diferentes perspectivas antropológicas que se han ocupado, de forma especial, del mundo de lo natural. Así, diferenciaremos tres grandes perspectivas: la ecológica, la simbólica cognitiva y la política. En la perspectiva ecológica revisaremos la elaboración antropológica del entorno, lo que se ha venido llamando ecología cultural. En cuanto a la perspectiva simbólico-cognitiva veremos la manera en que se ha utilizado como construcción cultural, observando las distintas interpretaciones y manifestaciones a las que ha dado lugar la noción de naturaleza. Y, por último, en la perspectiva política, analizaremos el papel otorgado a la naturaleza en la distribución de relaciones de poder significativas. Todo para situar a las perspectivas de la ecología simbólica y ecología política como los enfoques, desde nuestro punto de vista, más pertinentes para abordar el conflicto medio ambiental, sin renunciar con ello a las aportaciones que se han venido haciendo desde la disciplina y que han permitido un debate constante sobre el entorno.

\section{Las perspectivas de la(s) naturaleza(s) en antropología}

El papel que se asignó a la naturaleza como eje fundamental en el discurso antropológico proporcionó a la disciplina tanto herramientas analíticas para la 
investigación como un marcador de identidad. La naturaleza cobró un lugar destacado epistemológicamente, ya que garantizaba tanto la posibilidad de establecer un primer proceso constitutivo de atribución de orden y sentido, como un primer marco de comprensión de los fenómenos que se pretendían estudiar. Así, la naturaleza actuaba como un polo tensional para construir un universo de significación y como una fuente primordial para la constitución sistemática de una cosmovisión del mundo. De ahí que, durante largo tiempo, se tendiera a definir la cultura por oposición a la naturaleza.

En algunos planteamientos, dicho eje se torna fundamental, como es el caso del funcionalismo psicobiológico de Malinowski (1944), donde podemos encontrar una versión de este tipo de interpretaciones. Sin embargo, Malinowski no fue el primero ni el único que tomó el modelo dualista como motor de su teoría. Antes que él los evolucionistas la habían consagrado para su esquema interpretativo de la evolución de la historia. Después, debates como el idealista-materialista, que coparon buena parte de las décadas de los 60 y 70 del siglo XX, escondían tras ellos la polémica entre naturaleza y cultura. De facto, la confrontación naturaleza/cultura es posible rastrearla hasta bien entrado el último cuarto del siglo XX. Podemos decir que tanto en la ecología cultural, como en las propuestas materialistas e incluso en algunas marxistas, se encuentra un esquema reduccionista sustentado en la dicotomía naturaleza-cultura. Del mismo modo, en la antropología estructuralista o simbólica, hallamos un esbozo similar basado en el binomio naturaleza-cultura pero, en este caso, como propuesta analítica para interpretar diferentes procesos sociales. Así, detrás de la aparente diferencia, entre el enfoque estructuralista y simbólico subyace una misma concepción basada en la polaridad (Descola y Pálsson, 1996). Las consecuencias que dicha representación ha traído consigo se pueden resumir fundamentalmente en dos: en primer lugar, el modelo dualista ha obstaculizado una visión ecológica de las relaciones entre los seres humanos y el medio ambiente (Hornborg, 1996; Descola, 1996; Hornborg y Pálsson, 2000) y, en segundo lugar, ha imposibilitado interpretar el conocimiento ecológico y tecnológico de otras culturas por estar las mismas supeditadas a las pautas de comprensión del modelo occidental (Hviding, 1996; Ellen, 1996).

Distintas aproximaciones han puesto en entredicho el modelo dualista, aduciendo que las diferenciaciones establecidas por el pensamiento científico 
occidental no son ni exportables a otros modelos culturales ni, necesariamente, se encuentran en ellos (Hornborg, y Pálsson, 2000). Desde la etnografía, Descola (1993, 1998, 2003), como veremos más adelante, ha puesto en evidencia cómo la dicotomía naturaleza-cultura pierde el sentido en algunas prácticas culturales. Siguiendo a esta crítica, numerosos autores han mostrado, en diferentes contextos etnográficos, cómo en distintos saberes locales no hay posibilidad de aplicar el dualismo culturanaturaleza, entrando en las cosmologías toda suerte de interrelaciones entre humanos, objetos, espíritus y animales (Arhem, 1996; Rival, 1996). Ello hasta el punto de que han puesto en duda que en algunas culturas exista realmente una categoría específica que haga referencia a lo que nosotros denominamos naturaleza (Howell, 1996). Pero la dicotomía naturaleza-cultura no sólo ha sido desacertada para el estudio de realidades no occidentales. Esta polaridad tampoco da cuenta de las relaciones existentes entre naturaleza y cultura en nuestra propia sociedad. Latour (1993) ha puesto en evidencia cómo en la práctica de la ciencia moderna nunca se ha superado el modelo dualista. Pese a que la constitución moderna se basa en la división entre el mundo natural y el mundo social (separación resultado de un proceso epistemológico de 'purificación' que crea dos zonas ontológicas diferenciadas), en realidad, al existir otro conjunto de prácticas que (por un proceso de 'traducción') permiten la multiplicación de los híbridos de la naturaleza y la cultura, la ciencia moderna nunca ha podido llegar a cumplir la máxima del modelo dualista; de tal forma que, nunca hemos sido modernos.

Por otro lado, la inconsistencia del modelo dualista también ha salido a la luz cuando se ha prestado una mayor atención a los procesos de elaboración científica, considerándolos como generadores de culturas locales y que están sujetos a tradiciones, a contextos productivos específicos y a relaciones de poder. Por poner un ejemplo, Nothnagel (1996) ha estudiado cómo la ciencia 'reproduce' la naturaleza, es decir, no sólo estudia los fenómenos dados 'naturalmente' sino que es capaz de reproducir artificialmente sus propios fenómenos. Asimismo, es evidente que la aparición de múltiples híbridos como la oveja Dolly, los bebés probetas, los alimentos transgénicos, etc., fuerzan a repensar los frágiles límites establecidos entre naturaleza y cultura (Santamarina, 2007). Autores como Haraway $(1995,1999)$ hablan de la reinvención posmoderna de la naturaleza, donde la iconografía del cyborg (un híbrido entre máquina y organismo) encapsularía ejemplarmente la disolución de límites : "el cyborg aparece mitificado precisamente donde la frontera entre lo animal y lo humano 
es transgredida" (Haraway, 1995:257). Y Papagaroufali (1996) considera que las prácticas biotecnológicas, como los xenotrasplantes y la transgénesis, cuestionan y jerarquizan las fronteras establecidas entre lo humano y lo animal.

Junto a lo señalado, el nuevo contexto de degradación medioambiental ha puesto sobre la mesa el debate sobre nuestras relaciones con el medio y con lo que consideramos el mundo de lo natural (Eder, 1996), unas relaciones fundamentadas en una visión del mundo dualista y jerárquica, que ha desencadenado una destrucción sin límites. Al reducirse la naturaleza simplemente a "la materia prima de la cultura, apropiada, reservada, esclavizada, exaltada o hecha flexible para su utilización por parte de la cultura en la lógica del colonialismo capitalista" (Haraway, 1995:341), hemos asistido a una dominación, ligada a la lógica de la producción y del capital, que permite la reducción sistemática de espacios (naturales, colectivos y discursivos) con total impunidad. La crisis medioambiental pone sobre la mesa la irresponsabilidad de nuestros cimientos y supone el quiebro del mito moderno de una dominación absoluta de la naturaleza (Santamarina, 2006a).

Con todo, antes de la deconstrucción del modelo dualista, se han producido en antropología numerosas contribuciones que suponen un importante legado para esta tradición de pensamiento. Tres perspectivas (ecológica, simbólica y política) agrupan las distintas aportaciones que se han ocupado especialmente del mundo de lo natural; de ellas nos ocupamos a continuación, viendo sus limitaciones y las propuestas que permiten superarlas.

\subsection{La perspectiva ecológica}

Al comenzar cualquier monografía clásica de antropología, lo primero que nos encontramos es un capítulo de introducción dedicado al hábitat y al entorno de la cultura observada. El medio donde se ha desarrollado la investigación y donde se desenvuelve la sociedad estudiada sirve como un primer marco de referencia, es el contexto que da sentido al texto. Sin embargo, eso no significa que los antropólogos hayan considerado siempre el entorno como un factor explicativo de los fenómenos culturales $^{2}$. La perspectiva ecológica no llega a la disciplina hasta los años cuarenta, va a ser entonces cuando se importen los primeros conceptos de la doctrina 
darwiniana (Valdés y Valdés, 1996). Las tensiones generadas entre la biología y la antropología hicieron posible el desarrollo de la ecología cultural. Este enfoque centró su atención en los procesos adaptativos de la cultura, entendiendo que las culturas se adaptan al medio, y que en ese proceso podemos ver cómo una cultura se constituye. El debate de los ecólogos culturales parece moverse en una discusión centrada sobre el determinismo cultural y el determinismo ambiental ${ }^{3}$. Comenzaremos con Kroeber, como un claro exponente de la concepción de la autonomía cultural en un espacio determinado; su obra perfila de manera ejemplar la tensión entre la biología y la antropología. Seguiremos con White, como continuador de la tradición boasiana y antecedente inmediato de la adopción de la perspectiva ecológica. El punto de inflexión viene dado por Steward, al que se le atribuye la paternidad de la ecología cultural. En él observaremos el primer intento de conjugar los factores biológicos con Ios culturales; por ello, se considera a este autor como una bisagra entre dos modos fundamentales de entender las relaciones entre naturaleza y cultura. Aunque, como veremos, sus continuadores, materialistas e idealistas, vuelven a situar en dos polos la naturaleza y la cultura respectivamente. Para terminar, nos aproximaremos a los enfoques principales a los que ha dado lugar el desarrollo de la ecología cultural: el sistémico y el individualista. Nos detendremos sólo en el sistémico, a través de la obra de Rappaport, para analizar las dificultades que arrastra la perspectiva ecológica y para tomar a este autor como puente hacia las nuevas ecologías (Biersack, 1999a).

Kroeber (1917) en su clásico artículo 'Lo superorgánico' delimita y contrapone cultura y naturaleza, siguiendo el camino iniciado por Boas, intentando tanto combatir las formulaciones de biólogos evolucionistas, como delimitar la cultura como un campo específico de investigación. Para él, la cultura es 'superorgánica', está por encima de lo orgánico, de lo natural. La frontera entre lo natural y lo cultural es trazada de forma clara y contrapuesta. La naturaleza, lo orgánico, pasa a ocupar un papel

\footnotetext{
${ }^{2}$ Más bien, dicha descripción se ha utilizado como una doble estrategia: permitía ubicar y dar realidad a una sociedad concreta. Eso legitimaba al antropólogo al reconocerse su conocimiento del terreno.

${ }^{3}$ Seguiremos para este bosquejo las periodizaciones de Orlove (1980) y Valdés y Valdés (1996). Orlove (1980) diferencia tres estadios en el desarrollo de la antropología ecológica: un primero caracterizado, por el trabajo de Steward y White; un segundo ocupado por las teorías neofuncionalistas y neoevolucionistas; y un tercero, donde se desarrollan las enfoques procesuales. Valdés y Valdés (1996) señalan tres etapas: una marcada por la discusión de los argumentos posibilistas y la aparición de la ecología cultural, otra caracterizada por el afán de fundar una disciplina más general, y que da lugar al enfoque sistémico y a la perspectiva individualista; y, por último, la etapa actual, en la que se produce una síntesis de los enfoques anteriores (homeostático y procesual). Por otro lado, hay que señalar que Milton (2001a) utiliza otro esquema para hablar del desarrollo de la perspectiva ecológica, aunque hemos preferido utilizar estos porque se ajustan más, desde nuestro punto de vista, a una visión global de las distintas etapas de la perspectiva de la ecología cultural.
} 
pasivo (el entorno tiene sólo un sentido delimitador, un papel negativo); es la cultura, lo supraorgánico, quien cobra el protagonismo (lo social es lo que determina lo social). En 1952, después de las fuertes críticas suscitadas por el valor otorgado a lo superorgánico, ofrece una definición de cultura más elaborada; sin embargo, los postulados no difieren de sus planteamientos anteriores. El esquema se repite: existe una 'natural' naturaleza de la cultura. Esta es quizás la frase que mejor resume el planteamiento de Kroeber.

Los planteamientos de Kroeber fueron muy atacados en su época, pero, como ha señalado Harris, "el más decidido apoyo a lo superorgánico de Kroeber llegó de un ángulo totalmente inesperado. En 'The expansion of the scope of science', Leslie White defiende a Kroeber como uno de los pocos antropólogos que se han esforzado por formular la filosofía de una ciencia de la cultura" (1987:287). La concepción de White parte de unas premisas muy parecidas a las de Kroeber, pero radicalizando aún más el determinismo cultural. Para él, la cultura sólo se explica a través de la cultura ([1959]1975b) puesto que la cultura tiene un desarrollo propio una vez se ha desprendido de su origen en la evolución biológica. La delimitación entre la naturaleza y la cultura queda establecida de forma precisa por la capacidad simbólica de los seres humanos ${ }^{4}$. En su teoría cobra especial importancia la relación entre la energía, la eficacia tecnológica y la evolución. Su modelo contempla tres subsistemas: el tecnológico, el social y el ideológico. De ellos, el tecnológico es el principal y explica la evolución de la cultura. Su esquema es sencillo: la evolución depende de la capacidad para aprovechar la energía que hay en el entorno, y esto se consigue a través del sistema tecnológico ${ }^{5}$. Dicha fórmula "contradice el postulado inicial de White. ¿Cómo argumentar que la cultura sólo se explica por la cultura si hay al menos un elemento exógeno que la determina?" (Luque Baena, 1990:98). Al definir la cultura le concede una autonomía propia pero, al explicar el desarrollo de la humanidad en términos tecnológicos-energéticos, da entrada al medio como un factor explicativo en la evolución cultural. Para White, la clave está en controlar los recursos naturales. La diferencia radica en que no es lo mismo apropiarse de ellos que aprovecharlos y transformarlos. El factor tecnológico se convierte en fundamental para explicar el

\footnotetext{
${ }^{4} \mathrm{La}$ cultura es "la clase de las cosas y acontecimientos que dependen de simbolizar, en cuanto son consideradas en un contexto extrasomático" (White, [1959]1975:139).

5 "La cultura se desarrolla según aumenta la cantidad de energía aprovechada per cápita al año, o según aumenta la eficacia de los medios instrumentales que ponen la energía en funcionamiento" ([1949]1993b:325).
} 
progreso, ya que la energía utilizada depende del mismo. El sistema tecnológico condiciona a los otros subsistemas, los convierte en subsidiarios; de ahí la critica a su determinismo tecnológico-mecánico. En definitiva, la evolución está condicionada por la facultad de extraer energía y por los diferentes grados de desarrollo tecnológico ${ }^{6}$. La metáfora orgánica le permite ver la cultura como un proceso evolutivo.

Si bien White introduce la perspectiva ecológica, al reconocer la influencia del entorno en la cultura, será Steward quien definitivamente integrará en su perspectiva las interrelaciones entre cultura y naturaleza, aunque seguirá anclado en el modelo dualista. Su aportación más notable reside en su conceptualización de la adaptación cultural y de las relaciones entre entorno y cultura, que permite el desarrollo del nuevo enfoque de la ecología cultural. Para Steward, el problema de la adaptación al entorno (ecología) del ser humano radica en que se introduce el 'factor superorgánico de la cultura'. De ahí que "el problema de explicar el comportamiento cultural del hombre es de un orden diferente al de explicar su evolución biológica. Los modelos culturales (...) no pueden analizarse del mismo modo que las características orgánicas" ([1955]1993:335). Crítica el papel minúsculo otorgado al entorno por parte de los antropólogos que, al dedicarse a la historia y la cultura, han obviado el medio, reservándole un 'papel secundario y pasivo'. Según él, el concepto normativo de cultura ha dejado de lado las adaptaciones ambientales, al considerarse que todo está determinado por la cultura. Pero, la cultura no sólo se explica por la cultura, sino también por el entorno. Así, se deshacía de la concepción circular de la cultura ofreciendo un nuevo paradigma, "la ecología cultural difiere de la ecología humana y social en la búsqueda por explicar el origen de modelos y características culturales que caracterizan áreas diferentes más que por derivar principios aplicables a cualquier situación cultural y ambiental. Difiere de las concepciones relativista neoevolutiva de la historia cultural en que introduce el entorno local como factor extracultural en la infructuosa suposición de que la cultura viene de la cultura" ([1955]1993:338) ${ }^{7}$.

White lo expresa en la siguiente fórmula $E \times T=C$, donde $E$ es la energía per cápita, $T$ la eficiencia para aprovecharla y $\mathrm{C}$ el grado de desarrollo cultural.

6 "Los sistemas culturales, igual que los del nivel biológico, tienen capacidad para crecer. Es decir, el poder de captar energía es también la capacidad de aprovecharla cada vez más. Así, los sistemas culturales, igual que los organismos biológicos, se desarrollan, multiplican y expanden" ([1949] 1993: 366).

7 Para Steward, los aspectos de la cultura son interdependientes, pero varía el grado y el tipo. El concepto de 'núcleo cultural' permite ver cómo existen elementos que están más vinculados a la subsistencia y a la economía (también en el núcleo se encuentran las pautas sociales, políticas y religiosas), aunque existen otros elementos secundarios que dependen de factores histórico-culturales, y que pueden dar una imagen distinta entre dos culturas que tienen un mismo núcleo. Así, "la ecología cultural presta especial atención a aquellas características con las 
Como han señalado Valdés y Valdés, "Steward admitía la actuación conjunta de una doble causalidad, la bioecológica y la cultural, pero fue incapaz de precisar los respectivos ámbitos de aplicación" (1996:98). De todas formas, fue el precursor de la problemática ambiental en la antropología, sentando tanto las bases para un posterior análisis del interaccionismo como estimulando el debate entre sus seguidores, divididos en dos posiciones extremas: el materialismo y el idealismo. La discusión entre ambas posturas, entre razón práctica y cultura, queda personificada en sus dos máximos exponentes, Harris y Sahlins respectivamente. Detrás de este debate aparece, una vez más, la dicotomización naturaleza/cultura o, si se prefiere, la reducción de una sobre la otra. Para el materialismo vulgar, la cultura se explica en términos de naturaleza. Para el idealismo, la cultura es autónoma, autodeterminante y explicable en sus propios términos.

El materialismo de Harris parte de considerar "que la vida social humana es una reacción frente a los problemas prácticos de la vida terrenal" (1982:11), y que, por tanto, el énfasis debe ponerse en la relación entre producción, reproducción y ecología. Los condiciones tecnoecológicas y tecnoeconómicas ocupan un lugar privilegiado en su formulación, ya que serán los factores responsables de la organización social y la ideología. Este determinismo infraestructural viene justificado porque los seres humanos no podemos cambiar las leyes de la naturaleza, estamos sujetas a ellas. La tecnología permite alterar las tasas productivas y reproductivas pero, aún así, queda sujeta a las leyes biológicas y ecológicas, y a la capacidad de cada hábitat de ser modificado. Los constreñimientos infraestructurales son los que determinan los componentes estructurales y superestructurales ${ }^{8}$. Ejemplo de su argumentación lo encontramos en su interpretación de los tabúes alimentarios (1989, 1997). Harris ([1985]1997) cuestiona los postulados de Lévi-Strauss, planteándose si los alimentos son buenos para pensar o para comer. Su respuesta es clara: "las gentes hacen lo que hacen por buenas y suficientes razones prácticas y la comida no es a este respecto una excepción" ([1985]1997:13). Así, las cosas, "la comida debe nutrir el estómago colectivo antes de poder alimentar la mente colectiva" ([1985]1997:14). Para él, los

que el análisis empírico muestra estar más estrechamente relacionado en la utilización del entorno de modos culturalmente prescritos" ([1955]1993:339).

8 "A la naturaleza le da lo mismo que Dios sea un padre amantísimo o un sanguinario caníbal. Pero no le es indiferente que el período de barbecho de un campo cultivado por el método de roza dure un año o diez"(1982:73). 
alimentos 'buenos para comer' son, sin duda, aquellos que tienen una relación coste/beneficio más óptimo en comparación con los que son 'malos para comer'. En esta relación coste/beneficio, nos dirá Harris, las culturas no sólo tienen en cuenta el valor nutritivo sino también el coste/beneficio ${ }^{9}$ de la producción y sus efectos sobre el medio. Las cocinas serán más carnívoras o más herbívoras dependiendo de las poblaciones, los hábitats y los recursos tecnológicos, de tal forma que todos los rasgos culturales tienen un sentido ecológico. El determinismo ambiental de su explicación es evidente al otorgar al ambiente un papel sobresaliente en el desarrollo de las culturas y al considerar los rasgos culturales como expresiones de la racionalidad adaptativa. En suma, el materialismo cultural enarbolado por Harris, reduce la cultura a la naturaleza, la ideología a la práctica, lo ideal a lo material, y todo desde un determinismo infraestructural que desvaloriza el orden cultural y que reduce sus explicaciones a la adaptación al medio por parte de los sistemas. Las críticas a esta perspectiva han sido numerosas, aunque el ataque más directo le viene formulado por Sahlins y Godelier ${ }^{10}$.

Nada más contrario al materialismo cultural que la posición adoptada por Sahlins, la cual queda bien recogida en Cultura y Razón práctica ([1976]1997). En su comienzo advierte: "este libro contribuye a una crítica antropológica de la idea de que las culturas humanas se formulan a partir de la actividad práctica y, subyacente a ella, del interés utilitario" (Sahlins, [1976]1997:9). Frente a la razón práctica, Sahlins propone la razón simbólica o cognitiva; frente al postulado de que los humanos nos movemos en un mundo material adopta la consideración de que somos los únicos seres que tenemos esquemas significativos. De ahí que parta de la premisa de que la cultura debe explicarse en términos de ella misma. Para él, las culturas son órdenes significativos sistemáticos y no pueden ser simplemente aleatorias invenciones de la mente. La cultura no puede ser vista como una variable dependiente de la lógica práctica, ni debe ser entendida a partir de las fuerzas materiales; más bien al contrario, los efectos materiales dependen de la interpretación cultural. Su postura frente a la naturaleza es justo la inversa a la de Harris, puesto que para él se produce

\footnotetext{
${ }^{9}$ Estos costes/beneficios se traducirían en las economías de mercado en 'bueno para comer, bueno para vender'.

${ }^{10}$ Las principales críticas de Godelier al materialismo vulgar se centran en subrayar el reduccionismo que establece Harris de las relaciones entre economía y sociedad, en su definición histórica como una serie de hechos con cierta frecuencia estadística y en su concepción del término adaptación. Volveremos a Godelier más adelante.
} 
una culturización de la naturaleza ('naturaleza culturizada'). La naturaleza es sólo materia prima en espera de que los seres humanos le den una forma significativa y un contenido. El orden cultural es el encargado de definir la naturaleza, en este sentido, las leyes de la naturaleza son indeterminadas. Esta concepción idealista reduce la naturaleza a la cultura, de la misma forma que el materialismo reducía la cultura a la naturaleza, e imposibilita pensar las relaciones naturaleza/cultura de otra forma que no sea la confrontación y el menoscabo de una por la otra. Sahlins, en su empeño de subrayar la dimensión ideológica, cae en la misma trampa que Harris.

Sin embargo, siguiendo con el desarrollo de la ecología cultural, vemos cómo en los años setenta dicha perspectiva se apartó de los presupuestos de Steward y puso mayor énfasis en los conceptos de adaptación y ecosistema. A ese nuevo enfoque se le ha denominando sistémico, por el acento puesto en la interrelación de factores dentro de un sistema que se considera autorregulado y funcional, y por el estudio de los factores que inciden en la conservación del equilibrio de un sistema. En Rappaport podemos apreciar el giro hacia esta nueva visión. El planteamiento inicial es justo el inverso del visto hasta ahora: se trata de establecer qué es lo que no es humano en vez de observar lo que es exclusivamente humano ${ }^{11}$. Así, al situar a los seres humanos como animales, se pueden adoptar las perspectivas ecológicas y biológicas en las generalizaciones antropológicas. El punto de partida es que "los hombres son animales, y como todos los animales están indisolublemente ligados a medios ambientes compuestos de otros organismos y sustancias inorgánicas de los cuales deben obtener materia y energía para sustentarse y a los cuales deben adaptarse para no perecer" (1975:269). Rappaport reconoce que en los seres humanos nos encontramos con adaptaciones culturales al medio, pero en el proceso de adaptación entran en juego las mismas reglas que podemos encontrar en la adaptación biológica. Esto abre las puertas para la adopción de una perspectiva ecológica. La complejidad está en las relaciones que se establecen entre naturaleza y seres humanos porque "aunque el hombre actúa en la naturaleza de acuerdo con sus conceptos y deseos, es sobre la naturaleza donde actúa, a la vez que ésta actúa sobre el hombre" (1975:271). El problema radica en las discrepancias que existen entre el 'modelo percibido' y el 'modelo operativo' en la comprensión de la naturaleza.

\footnotetext{
11 "Aunque la antropología ecológica comparte con el resto de la antropología cultural el objetivo de esclarecer la cultura humana, difiere en una gran parte de aquella en que intenta explicar la cultura en términos de la parte que juega en los aspectos de la existencia humana que son comunes a los seres vivientes" (Rappaport, 1975:268).
} 
El trabajo de los antropólogos ecólogos será integrar ambas perspectivas para 'evaluar la capacidad adaptativa'. Para Rappaport todo puede ser explicado como un proceso adaptativo.

El neofuncionalismo de Rappaport se hace evidente en su explicación. Toda la argumentación responde a un mecanismo discursivo circular: la adaptación cultural al medio contribuye a mantener el equilibrio en el ecosistema porque es adaptativa. Al partir de una inversión (de la especificidad humana se pasa al énfasis de su condición de animal), legitima su posición de adoptar el lenguaje de la ecología para explicar la cultura; los seres humanos como seres animales no escapan al natural proceso adaptativo de cualquier especie. El medio condiciona todas las relaciones de los seres humanos. La tensión entre ecología y cultura se resuelve a favor del primero. La cultura es un factor independiente que funciona como instrumento de adaptación a la naturaleza. Si bien reconoce la influencia entre ambas, parece que, en última instancia, el medio impone restricciones. El enfoque sistémico reduce las interrelaciones a constricciones en aras de un sistema equilibrado y autorregulado ${ }^{12}$.

En resumidas cuentas, podemos decir que la perspectiva ecológica tradicional arrastra serias dificultades teóricas. Desde diversas ópticas encontramos críticas a los planteamientos de la ecología cultural. El uso de la terminología de la ciencia ecológica aplicada al estudio de la cultura genera más de un problema, empezando por el polémico proceso de adaptación. El concepto implica que existen una serie de rasgos que son adaptativos y otros inadaptativos; la dificultad está en establecer qué condiciones son las que nos permiten atribuir las mencionadas características. Como señala Godelier, "hay que concebir la adaptación y la inadaptación como dos aspectos de una misma realidad dinámica, movida por sus propias contradicciones" (1989:59). Además, el enfoque ha dejado de lado aspectos tan importantes como el conflicto o como la construcción social de las relaciones con el medio. La tensión entre ecología

\footnotetext{
${ }^{12}$ Tal enfoque será sustituido a finales de los setenta por la ecología evolutiva, una perspectiva individualista, que bebe tanto de la teoría evolucionista y genética como de los modelos matemáticos. Las unidades de análisis ya no serán las poblaciones sino los individuos, y el interés se centra en ver cómo un organismo individual es capaz de desarrollar estrategias para resolver la adaptación al entorno. En los ochenta este enfoque conducirá a un análisis procesual de las sociedades cazadoras-recolectoras (Optimal Foraging Theory). El presupuesto de esta teoría es que la conducta depredadora ha sido proyectada por selección natural como adaptación a las situaciones cambiantes, y que las respuestas procuran el mayor beneficio posible. Es decir, se trata de observar a qué problemas se enfrenta un depredador para ver qué estrategias pone en marcha el individuo para asegurarse la supervivencia y la reproducción. Según Valdés y Valdés, "las últimas investigaciones ecológicas en antropología apuntan a una síntesis de estos dos enfoques, el sistémico y el individualista [...] La tendencia es abandonar la concepción monolítica tanto del entorno como del organismo que se adapta a él y considerar la variabilidad tanto ambiental como individual" (1996:101).
} 
y cultura sólo se resuelve en el plano simbólico a través de la denominación de este enfoque como 'ecología cultural'. Detrás se evidencian las dificultades de conceptulizar la naturaleza y la cultura. Tras el determinismo ambiental, cuyo debate se centraba en el modo en que la naturaleza actuaba sobre la cultura, y el enfoque sistémico basado en el ecosistema, cuya premisa consideraba a la naturaleza y la cultura como independientes pero en un sistema de influencia mutua, subyace un mismo esquema dualista que permitía a los antropólogos tener un primer marco de referencia para su interpretación (Milton, 2001b:17). Pese a que el planteamiento iniciado por Steward intentaba establecer las interrelaciones entre ambas, la naturaleza y la cultura se siguen viendo como realidades diferenciadas. El esquema pasa de la mera confrontación a la búsqueda de influencias mutuas, pero ese reconocimiento no escapa de la visión de dos entidades autónomas relacionadas externamente.

A finales de los 80 y a lo largo de los 90, se aprecia un cambio profundo de esta perspectiva. Biersack (1999a) expone que las nuevas ecologías han dejado de lado los viejos debates (materialismo/idealismo) y dicotomías del pasado (naturaleza/cultura). Al mismo tiempo, los flujos transnacionales y la articulación localglobal han contribuido a un cambio que ha dado lugar a nuevas perspectivas. La obra de Rappaport representa -para Biersack- el puente entre el pasado, marcado por el materialismo reduccionista, y el presente, caracterizado por una ecología neomaterialista. En este sentido, lo considera como el precursor de las emergentes ecologías actuales y como el antecedente inmediato para entender la nueva dirección de la antropología ecológica. Para él, las nuevas ecologías beben de muy distintas fuentes y, aunque se enmarcan en el contexto de las viejas ecologías, se distancian de ellas al incorporar diferentes tradiciones analíticas (economía política, antropología simbólica y antropología histórica). Pese a la dificultad de establecer sus genealogías, el autor reconoce el legado rappaportiano en las mismas, de ahí que se convierta en puente. Según Biersack, las críticas suscitadas tras la publicación de Cerdos para los antepasados, en el contexto de la controversia entre materialistas e idealistas, fueron contestadas por Rappaport mediante dos textos claves: Ecology, Meaning and Religion (1979) y en el epílogo de la nueva edición de Cerdos para los antepasados (1984). En ellos, el autor se distancia del funcionalismo y del reduccionismo materialista de su obra, desarrollando una hipótesis sobre la complejidad de la 
condición humana. Rappaport redefine, en estos escritos ${ }^{13}$, su ecología, ya no habla en términos de la utilidad adaptativa de la cultura, sino que la considera como un aparato heurístico que permite poner al descubierto los aspectos disfuncionales de las relaciones ser humano-naturaleza, insistiendo en la complejidad de la condición humana, que es al mismo tiempo significante y natural. Para Biersack, "Rappaport había llegado a la conclusión de que la vida es intersticial, a caballo entre la Naturaleza y la Cultura. Ser humano exige vivir la relación entre la Naturaleza y la Cultura y habitar un mundo basado en esa relación" (1999a:7). Dicha reorientación, no determinista y no reduccionista, sienta las bases para el desarrollo de nuevas ecologías, al distanciarse de la disyuntiva entre idealismo y materialismo y al introducirse en el terreno de la ecología política.

La deconstrucción del modelo dualista y los cambios actuales han forzado a repensar las proposiciones reduccionistas del pasado. En el contexto de la globalización, la nueva antropología ecológica, o medio ambiental, debe diferenciarse de la de antaño no sólo por las nuevas unidades analíticas y los métodos utilizados, sino por su conciencia política frente a la vieja antropología ecológica (Kottak, 1999). Para Kottak, los antropólogos son testigos de las amenazas externas que sufren las personas estudiadas y no pueden, ni deben, quedarse indiferentes. De ahí que aparezcan nuevas orientaciones, como la ecología política, más comprometidos con la realidad que viven.

En definitiva, podemos decir que la antropología adoptó pronto el modelo ecológico, dando al entorno un papel protagonista, aunque dicha incorporación no estuvo exenta de serias dificultades teóricas y metodológicas. El nuevo giro de la ecología cultural hacia nuevas ecologías (simbólica, histórica, y política) pone en evidencia la necesidad de romper las dicotomías de antaño y la urgencia de explorar nuevos campos de análisis más acordes con la transformación del mundo de hoy.

\subsection{Perspectiva simbólica-cognitiva}

Como venimos apuntando, en la disciplina ha habido un esfuerzo por situar diferencialmente su producción respecto a otras disciplinas y otros objetos. Las

\footnotetext{
${ }^{13}$ En su último libro, Ritual y Religión (1999), podemos ver claramente el cambio en los planteamientos de Rappaport. 
características intrínsecas de lo 'humano' han permitido extraer las condiciones necesarias para la constitución de una forma de vida distinta a la de otros seres. El énfasis se ha puesto en la diferencia, dando paso a una reflexión sobre la alteridad (quiénes, cómo, qué somos y quiénes, cómo, qué son los otros). En dicha elaboración encontramos un dispositivo clásico en la construcción de identidades: nos asimilamos a la naturaleza (otro) y la establecemos como parte integrante de lo nuestro; y la expulsamos de lo nuestro, marcando límites que nos diferencien de un todo. La expresión de la búsqueda de la naturaleza humana resume esta doble estrategia y, en este sentido, lo simbólico ha jugado un papel destacado como marca de diferencia.

Cassirer, desde la antropología filosófica, se plantea qué es lo que realmente nos distingue del resto de organismos; para él la respuesta está en el modo, tanto cuantitativo como cualitativo, de adaptarse al medio. Los seres humanos experimentan con respecto a los animales una realidad no sólo más amplia sino también distinta ${ }^{14}$. Los seres humanos retardan su respuesta al medio porque el individuo "ya no vive solamente en un puro universo físico sino en un universo simbólico" (1965:47). Esta es la diferencia fundamental entre los dos mundos, el natural y el cultural. Gracias al simbolismo Cassirer puede establecer una frontera nítida entre dos formas de vida. La posibilidad de establecer la 'clave de la naturaleza del hombre' la realiza a través de la diferencia. La alteridad se construye frente a los 'otros seres' al ofrecernos el referente necesario para pensarnos. En Cassirer podemos ver cómo dentro del modelo dualista la naturaleza ha sido utilizada como delimitadora y sustentadora de un orden diferente que permite hablar desde un lugar distinto del mundo natural, situándonos en un plano opuesto al resto de los 'otros' por nuestras propias características constitutivas. El situar lo animal frente a lo cultural (somos seres simbólicos) proporcionaría un primer esquema analítico. Pero las aportaciones más relevantes en el campo simbólico-cognitivo han venido de la consideración de la naturaleza como modelo de orden y clasificación, y como esquema analítico para la comprensión de múltiples procesos sociales. En este sentido, destaca el estructuralismo de Lévi-Strauss. En su teoría, el par naturaleza/cultura juega un papel fundamental como principio metodológico (LéviStrauss, [1962]1988:358), aunque su consideración de la naturaleza y cultura va

\footnotetext{
14 "Existe una diferencia innegable entre las reacciones orgánicas y las respuestas humanas. En el caso primero, una respuesta directa e inmediata sigue al estímulo externo, en el segundo la respuesta es demorada, es interrumpida y retardada en un proceso lento y complicado de pensamiento" (1965:47)
} 
modificándose a través del tiempo. Dicho eje atraviesa toda su argumentación en dos sentidos: en primer lugar, el paso de la naturaleza a la cultura instaura la norma y el orden; en segundo lugar, aparece como base para comprender los procesos mentales y los principios organizativos de categorización y diferenciación social a partir de los objetos naturales.

En Las estructuras elementales de parentesco ([1949]1981) podemos ver cómo el puente entre naturaleza y cultura constituye el cimiento, no sólo de su teoría del parentesco, sino también de toda su concepción antropológica. Para Lévi-Strauss, el átomo de parentesco es la alianza, o en negativo, la prohibición del incesto y la función de esta prohibición consiste en impulsar el intercambio recíproco de las mujeres. El incesto se elevará a la expresión de un principio universal de reciprocidad y, aunque éste no sea un principio explicativo, sí lo será orientativo. Además, el principio de reciprocidad es remitido finalmente a la estructura mental subyacente. Lévi-Strauss parte de formular una cuestión clave en su interpretación, “¿Dónde termina la naturaleza? ¿Dónde comienza la cultura?" ([1949]1981:36). Él mismo dice que es imposible saber dónde se produce el pasaje de una a otra. Sólo sabemos que, cuando aparece la regla, estamos hablando de cultura y que, cuando tomamos como criterio lo universal, hemos atravesado la frontera de la naturaleza. Así, pasa a demostrar que la prohibición del incesto cumple los dos criterios que definen tanto a la cultura como a la naturaleza: la regla y la universalidad. La regla del incesto es social pero, al mismo tiempo, es presocial por la universalidad y por el tipo de relaciones que impone su norma. La prohibición se encuentra en el umbral de la cultura, en la cultura y es la cultura misma. No tiene un origen cultural o natural, constituye "el pasaje de la naturaleza a la cultura (...) el vínculo de unión entre una y otra" ([1949]1981:59). Supone el nacimiento de un nuevo orden al superarse 'la naturaleza a sí misma'. De modo que el incesto representa "el pasaje del hecho natural de la consanguinidad al hecho cultural de la alianza" ([1949]1981:66) ${ }^{15}$. En este sentido, el incesto instaura la regla (domestica el azar) al establecer un orden que inaugura la organización. La prohibición del incesto es el estigma del principio de organización. Supone un sistema de prestaciones y contraprestaciones que conecta a los miembros entre sí. La regla

\footnotetext{
${ }^{15}$ La misma naturaleza actuaría bajo el doble principio de dar y recibir, que se traduce en la oposición de matrimonio y filiación. La alianza está más libre puesto que la naturaleza no le fija su contenido; inversamente, la filiación se halla determinada por la naturaleza. La alianza se presenta como el único fenómeno universal sobre el que la naturaleza no ha acabado de decirlo todo, la impone pero sin determinarla. El papel desempeñado por la cultura es el de sustituir el desorden por la organización.
} 
permite afirmar lo social sobre lo natural, lo colectivo sobre lo individual, lo organizado sobre lo caótico. La exogamia es la expresión social ampliada del incesto. Ambas, exogamia e incesto, son en lo formal idénticas para Lévi-Strauss. El contenido negativo que se esconde tras ellas, se transforma en motor insustituible de intercambio. De manera que la exogamia representa el arquetipo de la reciprocidad, mientras que el incesto se transforma en la donación por excelencia y en carácter total de todo sistema de parentesco ([1949]1981). El vínculo de la alianza asegura la primacía de lo social sobre lo biológico, lo cultural sobre lo natural ${ }^{16}$. El incesto se convierte en el principio de la cultura y en el final de la naturaleza. Una metáfora del eslabón perdido que le permite situar a la cultura sobre la naturaleza, una concepción del tránsito de una a otra que es, a la vez, evolutiva y brusca. La cultura se sitúa en el orden, la regla es su identificación por excelencia. La naturaleza se ubica en el desorden, la universalidad es su característica. $Y$ el incesto bebe de ambas, abriendo paso a la alianza, a la familia; en definitiva, a la sociedad. Vemos, pues, cómo el eje naturaleza/cultura se convierte en el principio que dota de sentido a su argumentación, aunque la brusquedad de dicha demostración hipotética (el paso de una a otra) no resulta muy convincente.

Pero, como ya hemos apuntado, en la obra levistraussiana la relación entre cultura y naturaleza es también clave en otro sentido. Si en el parentesco veíamos el tránsito entre naturaleza y cultura, ahora veremos cómo el pensamiento se convierte en 'mediador' entre ambas esferas. Para Lévi-Strauss, la naturaleza ofrece a los seres humanos un esquema de intelección que éstos ciertamente aprovechan, "el mundo vegetal y el mundo animal no son utilizados solamente porque se encuentren ahí, sino porque proponen al hombre un método de pensamiento (...) la vinculación real entre los dos órdenes es indirecta, porque pasa por la mente" ([1962]1997:26) $)^{17}$. La evolución de un conocimiento sistemático no puede deberse de forma exclusiva a su uso práctico (satisfacer las necesidades), sino que su desarrollo se corresponde

\footnotetext{
${ }^{16}$ Lenguaje e incesto jugarán para el autor el mismo papel universal ([1949]1981:571), mientras que lenguaje y exogamia cumplen la misma función de comunicación entre los hombres.

17 Según Malinowski o Radcliffe-Brown, todo animal totémico podía ser explicado por el principio de 'bueno para comer'; sin embargo, para Lévi-Strauss dicha teoría no deja de ser una imagen simplista del tótem que, en cierta medida, se corresponde con las visiones tradicionales acerca de los pueblos salvajes o primitivos. En dicho sentido aclarará "nunca y en ninguna parte, el 'salvaje' ha sido, sin la menor duda, ese ser salido apenas de la condición de animal, entregado todavía al imperio de sus necesidades y de sus instintos, que demasiado a menudo nos hemos complacido en imaginar $y$, mucho menos, esa conciencia dominada por la afectividad y ahogada en la confusión y la participación" ([1962]1988:69).
} 
más bien a exigencias intelectuales ${ }^{18}$. El sistema totémico se revela como una reflexión particular que permite el ordenamiento y la clasificación de la realidad. El mundo natural ofrece al mundo social una nomenclatura privilegiada para denotar y no sólo se utiliza porque existe sino porque sirve como método de pensamiento. El totemismo permite establecer principios de categorización y diferenciación social, por lo que resulta absurdo considerarlo un mero recurso primitivo. Además, el hecho de establecer un orden está en la base de todo pensamiento; por tanto, el pensamiento salvaje no hace otra cosa que hacer suya la exigencia de orden. La gran virtud del totemismo es adoptar códigos que permiten la transformación de mensajes de diferentes niveles. Una de las funciones principales del operador totémico será la "mediación entre naturaleza y cultura" ([1962]1988:136). La naturaleza se convierte en objeto de pensamiento y ofrece un modelo de diferenciación para la cultura: "el totemismo establece una equivalencia lógica entre una sociedad de especies naturales y un universo de grupos sociales (...) la división natural y la división social son homólogas; y la elección de la división en un orden implica la adopción de la división correspondiente en el otro, al menos como forma privilegiada" ([1962]1988:155). Así, se establece una homología entre dos sistemas de diferencias, uno en la naturaleza y otro en la cultura. Los seres humanos se valen de mediadores para superar la oposición naturaleza/cultura y poder pensar en términos de totalidad organizada. Las taxonomías y clasificaciones que operan en los sistemas indígenas resultan al final ser, en el plano de lo formal, idénticas a las utilizadas por el biólogo. Lévi-Strauss se esfuerza en demostrar la semejanzas que existen entre el pensamiento salvaje y el científico ${ }^{19}$, reconociendo que "el sistema entero del conocimiento humano cobra, así, un carácter cerrado" ([1962]1988:390).

Pero el estructuralismo lévistraussiano no ha sido el único en reparar que el mundo natural ofrece un modelo de pensamiento para el mundo social, a partir de la confrontación naturaleza-cultura. En este sentido, el libro que mejor recoge esta tradición quizás sea el de Douglas, Símbolos Naturales. Como la autora reconoce "el título de este volumen encierra a primera vista una contradicción. La Naturaleza se

\footnotetext{
18“Se comprende que las especies naturales no sean elegidas por 'buenas para comer' sino por 'buenas para pensar"' ([1962]1997:131).Como ya vimos dicha permisa será contestada por el materialismo cultural (Harris, [1985]1997).

${ }^{19}$ La diferencia entre tipos de conocimiento (salvaje/científico) se diluye, según Lévi-Strauss, porque ambos constituyen "los dos niveles estratégicos en que la naturaleza se deja atacar por el conocimiento científico: uno de ellos aproximativamente ajustado a la percepción y la imaginación y el otro desplazado" (Lévi-Strauss, [1962]1988:33).
} 
conoce por medio de símbolos (...), artificios y convencionalismos, y, por ello, contrarios a lo natural" ([1970]1988:13). La naturaleza se interpreta por medio de símbolos fundados en la experiencia y los símbolos son una elaboración del pensamiento. No tiene sentido, pues, hablar de un sistema 'natural' de símbolos naturales. En primer lugar, porque todo sistema de símbolos se desarrolla en un contexto particular, se rige dentro de un esquema general más amplio y con unas normas particulares; en segundo lugar, porque las propias características de una cultura los hacen diferentes; y tercero, porque la propia estructura social condiciona aún más la diversificación. Su argumentación acaba siendo paradójica: parte de una culturización de la naturaleza y su demostración se convierte en una naturalización de la cultura. El problema reside en que, a veces, aplica una definición antropológica al término naturaleza y otras se rige por el lenguaje común. Al final, resulta que la cultura construye sistemas simbólicos a partir de la experiencia de la naturaleza, y que la naturaleza ofrece un 'sistema natural' de símbolos, "la búsqueda de símbolos naturales se transforma así, en la búsqueda de sistemas naturales de simbolización" ([1970]1988:14).

Douglas inicia su propuesta distanciándose de Lévi-Strauss, aunque el modelo aplicado no deja de ser muy diferente en el plano de lo formal. Sigue un estructuralismo de corte durkheimiano, al considerar que no es la mente, con las oposiciones binarias, la que determina la aprehensión, sino la propia estructura social quien prescribe la forma en que conocemos. Según ella, el cuerpo social determina la experiencia del cuerpo físico, en la medida que la imagen que tenemos de éste se corresponde con una determinada experiencia social. Las categorías a través de las cuales percibimos el cuerpo se corresponden con las categorías sociales ${ }^{20}$. Lo importante es señalar que "el cuerpo físico puede tener un significado universal sólo en cuanto sistema que responde al sistema social" ([1970]1988:107). No existen símbolos naturales que no respondan a la experiencia de una estructura social. De hecho, los símbolos naturales permiten manifestar la relación que se establece entre el individuo y la sociedad, simbolizan la correspondencia de las partes con el todo. Así, Douglas invita a una reflexión sobre las categorías culturales a través de las cuales los sistemas simbólicos persiguen la construcción de un orden. Los símbolos

\footnotetext{
${ }^{20}$ Existe "una tendencia natural a expresar determinado tipo de situaciones por medio de un estilo corporal adecuado a ellas. Esa tendencia puede calificarse de natural en tanto que es inconsciente y se obedece a ella en todas las culturas" (Douglas, [1970]1988:93).
} 
expresan la cosmología de una sociedad, establecen las directrices, y con ellas, las normas y el control social. Las categorías sociales se expresan por símbolos 'naturales construidos' pero, a su vez, parece como si existiera, en su explicación, un 'natural' sistema de 'símbolos naturales' que facilitaría la correspondencia de categorías. Es preciso retener que Douglas, al igual que Turner, como veremos a continuación, considera que se produce una culturización de la naturaleza.

En Turner ([1967]1980) podemos ver otro ejemplo de la utilización de la dicotomía naturaleza-cultura como marco analítico para la interpretación. En cada ritual, nos dice, podemos encontrar una teleología propia con unos fines determinados, siendo los símbolos los vehículos a través de los cuáles se pueden alcanzar esos fines. Los símbolos son representaciones sociales, hechos sociales. Así, ve las celebraciones rituales "como fases específicas de los procesos sociales por los que los grupos llegaban a ajustarse a sus cambios internos y adaptarse a su medio ambiente" ([1967]1980:22). Para Turner, lo importante es establecer de partida cuáles son las características propias de los símbolos rituales. Estos presentan tres rasgos fundamentales: la propiedad de condensación; la capacidad de unificar significados dispares; y la polarización de sentido. Este último está referido a los dos polos de sentido: uno ideológico y uno sensorial. En el primero, los significados se refieren a elementos de los órdenes moral y social, se encuentra en él una distribución de las normas y valores de la sociedad, los principios de organización social; en el segundo polo, los significados están referidos a fenómenos naturales o fisiológicos, existe una correlación entre el contenido y la forma externa del símbolo. Los símbolos son multirreferenciales, "su cualidad esencial consiste en su yuxtaposición de lo groseramente físico con lo estructuralmente normativo, de lo orgánico con lo social" (Turner, [1967]1980:33). Dicha culturización de la naturaleza, expresada a través de los símbolos, es lo que para Turner hace posible la aceptación del sistema social. Los símbolos rituales son medios para conducir la realidad social y natural ([1968]1990). El ritual, a través de sus símbolos, pone de relieve elementos de su cultura y, a su vez, los relaciona con regularidades naturales y fisiológicas. Es una 'representación económica' de aspectos fundamentales, "en la medida en que representa la destilación o la condensación de muchas costumbres seculares y de muchas regularidades naturales" (Turner, [1967]1980:55). Los símbolos son capaces de aglutinar, por un lado, referentes de carácter natural y, por otro, los principios que 
rigen la sociedad. Dicha particularidad hace que un mismo símbolo represente conjuntamente lo moral y lo material, lo obligatorio y lo deseable ${ }^{21}$. La cultura socializa a la naturaleza, en la medida en que la experiencia fisiológica de los humanos sirve como fuente de configuraciones primarias que le permiten una primera taxonomía para interpretar la realidad. Los símbolos son capaces de encapsular lo groseramente físico con lo normativo estructural.

En definitiva, el modelo dualista es evidente detrás de las explicaciones de Douglas y Turner; además, sería injusto no reconocer la notable influencia que estos autores recibieron del legado levistraussiano. De hecho gracias al trabajo de LéviStrauss, se estimularon los estudios simbólicos sobre los objetos y animales naturales como modelos de organización social. Y fue precisamente un alumno suyo, Descola, quien introdujo una nueva perspectiva, al conjugar la antropología simbólica con la antropología ecológica, dando como resultado el desarrollo de la ecología simbólica ${ }^{22}$. Pero, quizás, el legado más importante de la obra de Descola ha sido cuestionar las argumentaciones clásicas de la antropología ecológica, lo que ha permitido una nueva reconsideración de la dicotomía entre naturaleza y cultura ${ }^{23}$. En sus trabajos este autor reconoce la influencia que ha recibido tanto del estructuralismo lévistraussiano como de la antropología marxista de Godelier, señalando que ambos le han enseñado que, para comprender las lógicas sociales, es necesario estudiar los modos materiales e intelectuales de la socialización de la naturaleza. Para él, la ecología ${ }^{24}$ debe ser entendida como un hecho social total, es decir, como una síntesis de elementos técnicos, económicos y religiosos. Por tanto, para comprender la socialización de la

\footnotetext{
${ }^{21}$ Turner pone, como ejemplo, la clasificación de los colores en el ritual ndembu, un sistema clasificatorio basado en una tríada de colores. En el contexto ritual, los colores son símbolos que representan la experiencia humana de lo orgánico, los productos del cuerpo humano, y esa experiencia física vinculada a los colores es, a su vez, expresión de las experiencias de las relaciones sociales. Además, los colores no sólo manifiestan las experiencias corporales, sino que suponen un esquema de clasificación fundamental de la realidad.

${ }_{22}$ Biersack (1999a) reconoce que Descola fue el primero en utilizar el neologismo 'ecología simbólica', aunque apunta que existieron numerosos antecedentes al mismo. Entre ellos destaca, como fundamental, el legado de Rappaport por su distinción entre modelos cognitivos y modelos operativos y por la importancia que otorga a la construcción de la naturaleza. No obstante, ve en la mitología de Lévi-Strauss, en la antropología simbólica de los 60 y 70, en la etnosemántica de los 50 y 60, y en el estudio de Mauss y Durkheim sobre la clasificación primitiva, los primeros pasos hacia la misma. Además, considera que el trabajo de MacCormak y Strathern (1980) fue el primero en explicitar que la naturaleza era una construcción socialmente variable. Por otra parte, señala que la ecología simbólica también ha sido influenciada por diferentes disciplinas que van desde la geografía cultural o la historia del arte, hasta la ecocrítica en literatura y los estudios de historia sobre la construcción histórica de la naturaleza.

${ }_{23}$ Anteriormente, Strathern (1980) ya había insistido en la necesidad de no interpretar bajo nuestros esquemas de naturaleza, cultura y sociedad a otras culturas, puesto que 'naturaleza y cultura' son productos culturales, no realidades dadas.

${ }^{24}$ Descola la define como "el estudio de las relaciones entre una comunidad de organismos vivos y su medio" (1986:15)
} 
naturaleza hay que combinar de forma indisoluble los aspectos materiales y los simbólicos, es imposible separar las determinaciones técnicas de las mentales.

Su punto de partida es rechazar las dos concepciones dominantes sobre las relaciones de los seres humanos con el medio, ya que una se caracteriza por el énfasis puesto en las producciones mentales, y la otra por la reducción de la práctica a la función adaptativa, ignorando todo significado. En contraste, Descola considera que, para acceder a las relaciones ser humano-naturaleza, es necesario observar las interacciones simbólicas entre las técnicas de socialización de la naturaleza y los sistemas simbólicos que las organizan. Así, muestra cómo la práctica social de la naturaleza se articula a la vez sobre la idea que la sociedad tiene de sí misma, sobre la idea que se hace de su medio ambiente natural y sobre la idea que se forma de su intervención sobre este medio ambiente. De su aportación, interesa resaltar, sobre todo, la ruptura de la dicotomía naturaleza/cultura. A través de su etnografía, demuestra la existencia de otros modelos culturales de aprehensión de la naturaleza alejados del nuestro. Al analizar el orden antropocéntrico de los achuar pone en evidencia que, en su construcción de la naturaleza, no existe división entre naturaleza y cultura; los animales, las plantas y los humanos pertenecen a la misma comunidad y están sujetos a las mismas reglas. La idea de la naturaleza como una realidad independiente es totalmente extraña en dicha comunidad; para ellos existe una continuidad entre los seres humanos y los seres de la naturaleza, entre el mundo cultural de la sociedad humana y el mundo natural de la sociedad animal. No existe una separación entre lo natural, lo humano y lo sobrenatural y esta continuidad es patente en símbolos, rituales y prácticas. Las relaciones sociales engloban a un todo. Como reconoce el propio Descola, ésta es una de las lecciones más importantes que ha recibido: "La naturaleza no existe en todas partes ni es eterna; o más exactamente, que esta separación radical establecida hace mucho tiempo por Occidente entre el mundo de la naturaleza y el mundo de los hombres no tiene mucha importancia para otros pueblos que confieren a las plantas y los animales los atributos de la vida social, los consideran como sujetos antes que como objetos y no sabrían, por tanto, expulsarlos a una esfera autónoma" (Descola, 1993:440). Y esta lección es, sin duda, una contribución fundamental para acabar con una dicotomía tan fuertemente instalada en nuestra práctica social y en la disciplina antropológica. La posibilidad de reconocer otros modelos locales de naturaleza ha supuesto iniciar un nuevo 
movimiento contra el reduccionismo etnocéntrico y contra los prejuicios presentes en las concepciones sobre las relaciones medio ambiente/ser humano.

Pero, Descola (1999) va más lejos, al concluir que la manera en que una sociedad conceptualiza sus relaciones con un medio dado es independiente de las características locales del ecosistema y de las técnicas de uso de los recursos ${ }^{25}$. Esta idea la justifica con dos ejemplos etnográficos, mostrando que sociedades con una organización social comparable, un ecosistema similar y unas técnicas idénticas, perciben sus relaciones con el medio ambiente de forma muy diferente; $y$, a la inversa, observando cómo sociedades que tienen ecosistemas completamente diferentes, con técnicas disímiles, perciben el medio de manera similar. Estos casos le llevan a preguntarse ‘¿de qué dependen entonces los valores?' ¿¿cuál es la naturaleza de los esquemas?'. Para él, los 'esquemas prácticos de la práctica' estructuran la forma en que se construyen las representaciones del medio y la manera en que se interactúa con él, de forma que existe una correspondencia estrecha 'entre los modos de objetivación y el tratamiento de los humanos' y 'los modos de objetivación y el tratamiento de los no humanos'. Los esquemas no son para Descola estructuras universales del pensamiento humano, sino más bien modelos mentales que orientan las relaciones con el medio y que varían en el tiempo y en el espacio. Horizontes éticos que cada cultura escoge privilegiando unas relaciones sobre otras.

El postestructuralismo de Descola ha contribuido de forma directa al replanteamiento del modelo dualista y ha influido en numerosos autores al situar el simbolismo y la ecología dentro de una perspectiva dinámica ${ }^{26}$. En esta línea, distintas aportaciones han puesto de manifiesto cómo existen otras formas de concebir las relaciones naturaleza-cultura. Howell (1996) ha señalado que el esquema dualista occidental debe considerarse, no tanto un principio universalista, como un ejemplo etnográfico, entre otros, de cómo los seres humanos construyen su identidad y su medio ambiente. En su trabajo sobre los chewongs muestra cómo dicho grupo mantiene una cosmovisión del mundo muy alejada de nuestro modelo:

\footnotetext{
25 "Una experiencia etnográfica en Amazonia me ha convencido finalmente de la idea que las ligaduras técnicas y ecológicas no son informaciones que existen fuera del pensamiento, y que las lecciones económicas de una sociedad son mayormente debidas a la manera en que sus miembros se representan la relación con los componentes orgánicos e inorgánicos de su entorno" (Descola, 1999:118).

${ }^{26}$ Como él mismo apunta, "comprender los mecanismos que hacen posible, en los diferentes contextos históricos, la actualización de estos esquemas de la práctica me parece que constituyen la tarea prioritaria de
} 
no existe ni una separación entre los seres humanos y los animales, ni entre el cuerpo y la mente, ni entre el mundo natural y el cultural. No tienen una categoría que haga referencia a lo que nosotros entendemos por naturaleza, las distinciones entre seres, objetos y plantas las establecen en función de si son personajes o no. Una frontera que, en cualquier caso, nos dice el autor, es fluida. Rival (1996), por su parte, en su estudio sobre los huaorani, pone en evidencia cómo en su cosmología no hay separación entre el mundo animal y humano, ambos se relacionan activamente. Y, por poner otro ejemplo, Arhem (1996) señala que entre los makunas no se da una división jerárquica entre la naturaleza y la cultura, sino un orden integrado donde los seres (humanos, espíritus, animales y plantas) están interconectados en una continuidad entre naturaleza y cultura.

En este sentido, la ecología simbólica ha permitido que lo simbólico y lo material dejen de ser vistos como dicotómicos, reconociendo que interactúan y que dicha interacción es la que tiene efectos en la realidad. Así, es posible descubrir que las relaciones humano/naturaleza son dialécticas, siendo el medio ambiente tanto un producto de esas relaciones como de sus sedimentaciones. Frente a las nociones clásicas de nicho y medio ambiente (caracterizadas por lo físico, estático, ahistórico, no relacional...), aparecen nuevas apuestas para definir el entorno. Tal es, por ejemplo, el caso de Biersack (1999b) que nos propone la noción de 'lugar' para una antropología de la naturaleza focalizada en la interacción de lo simbólico y la realidad física ${ }^{27}$. El lugar entendido como una construcción discursiva y material, es decir, como un producto de la imaginación humana y de la historia, pero también una realidad material producida por las relaciones sociales ${ }^{28}$.

Para concluir, podemos decir que la dimensión simbólica de la naturaleza cobra hoy un nuevo protagonismo, al poner en evidencia que existen muchos modos de edificar las relaciones ser humano/naturaleza y al sacar a la luz las prácticas, las instituciones y los discursos que condicionan nuestra percepción del medio. La percepción dualista se sustenta, desde la época clásica, en la filosofía moral de

\footnotetext{
una ciencia social renovada que no hace más distinciones entre los objetos de la antropología, de la historia y de la sociología" (1999:128).

27 Define el lugar como un término flexible que analice las articulaciones local/global y la dialéctica entre lo simbólico/lo material.

${ }^{28}$ Biersack (1999b) realiza un estudio sobre la minería de oro en Papúa Nueva Guinea siguiendo los modelos cognitivos de Rappaport. En el mismo señala que, para poder interpretar la cosmología y mitología actual de los paielas, es necesario entender que se trata de modelos cognitivos híbridos resultado del conjunto de las relaciones entre lo simbólico y lo material.
} 
occidente y trae consigo una jerarquización que legitima distintos campos de dominación. El desarrollo de la ecología simbólica abre las puertas de una crítica más rigurosa sobre nuestro sistema de representación del mundo. Esta desmantelación sistemática de categorías interpretativas que han condicionado los discursos etnográficos, es un primer paso hacia una antropología crítica.

\subsection{Perspectiva política}

La dimensión política de la naturaleza ha sido obviada durante largo tiempo en la disciplina antropológica. La dicotomía naturaleza-cultura y el reduccionismo implícito que conllevaba no fue superado hasta mediados de los ochenta. Además, en este periodo, el aumento de los problemas y desastres ecológicos provocó una respuesta por parte de diferentes perspectivas teóricas. El postmodernismo, el feminismo o el marxismo, se hicieron participes de la discusión sobre la crisis ecológica impulsando el desarrollo de la ecología política. En la práctica antropológica, la ecología política es un nuevo enfoque que introduce en sus análisis las relaciones entre economía, ecología y poder, alejándose de las viejas ecologías al considerar las relaciones locales/globales y al partir del presupuesto de que el mundo de hoy se caracteriza por flujos constantes que no permiten seguir viendo a las culturas como islas. En este sentido, ha sabido incorporar a sus trabajos diferentes aproximaciones y disciplinas, como la crítica posmoderna a las concepciones clásicas de la cultura y del trabajo de campo (Clifford y Marcus, 1991), que han supuesto un movimiento de renovación; las aportaciones de Foucault $(1991,1994,1997)$ a la investigación sobre las interrelaciones entre poder/saber/discurso, su concepción de la gubernamentalidad y su contribución al estudio de las técnicas y aparatos disciplinarios, que han puesto de manifiesto la necesidad de prestar una mayor atención a los mecanismos de poder; las nuevas propuestas marxistas en el análisis de lo ecológico, como la capitalización de la producción y de la representación. (O'Connor; 1992, O'Connor, 1994), que ha contribuido a desarrollar la necesidad de profundizar sobre lo ecológico en los conflictos sociales; o las críticas surgidas del feminismo, como las elaboradas por Holland-Cunz (1996), Mies y Vandana $(1997,1998)$ o, desde una posición contraria a éstas últimas las de Salleh (1994 y 1995) y Molyneux y Steinberg (1994). De dichas elaboraciones se ha sabido beneficiar la perspectiva antropológica de la ecología 
política, que se distancia de la ecología simbólica al conceder mayor importancia a la politización de las representaciones y al papel jugado por los discursos con sus efectos políticos y materiales. Buen ejemplo de ello es la ecología política postestructural de Escobar (1995b), quien considera el discurso, no como un reflejo de la realidad, sino como la constitución de la realidad misma. Para él, la comprensión cultural dominante, la narrativa, define los tipos de comportamiento deseables y razonables y la forma de los modelos de uso de los recursos.

Según Comas D’Argemir (1998) es difícil determinar los precedentes en el desarrollo de la ecología política en la antropología si bien los autores más citados son: Wolf, que aplica por primera vez el término de ecología política ${ }^{29}$, y Polanyi y Geertz, que realizan sus trabajos bajo esta perspectiva ${ }^{30}$. Siguiendo a Comas, en la obra de Polanyi La gran transformación (1944) encontramos un análisis que se aproxima mucho a la ecología política actual. En él, el autor se plantea cómo el mercado capitalista convierte a la naturaleza en mercancía, y cómo en una sociedad dominada por la lógica del mercado se subordina lo social a la obtención del máximo beneficio. Por su parte, Geertz (1963), plantea que para comprender la involución agrícola, el proceso que produce una intensificación del trabajo para conseguir rendimientos, es necesario atender a los factores políticos, la colonización y la independencia.

Pero, sin duda, en la obra de Wolf (1982), podemos ver sintetizadas las aportaciones a la ecología política. Entre ellas nos parece fundamental resaltar dos. En primer lugar, el énfasis puesto en las conexiones entre lo local y lo global, con el objeto de sacar a la luz que "la gente que dice que la historia le pertenece como la gente a quien se le ha negado la historia afloran como participantes en la misma trayectoria histórica" (Wolf, 1982:39). Así, insiste en que es necesario considerar al mundo como un todo de relaciones. En este sentido, Wolf considera que la hegemonía ideológica reduce los nombres (naciones, culturas, etc.) a cosas para la dominación ${ }^{31}$. Desde esta consideración, deconstruye el concepto de historia eurocéntrico, viendo cómo la historia ha sido edificada como un modelo de

\footnotetext{
${ }^{29}$ Siguiendo a Comas (1998), Wolf utiliza el concepto de ecología política, por primera vez, en 1972, en una ponencia en la que se relaciona los sistemas de propiedad y transmisión con las formas de aprovechamiento de los recursos, analizando los factores económicos y políticos globales que inciden en los sistemas locales.

${ }^{30}$ Ahora bien, apunta que si tomamos como antecedentes los autores que han relacionado ecología y política habría que incluir a muchos más, como F. Barth y J. Friedman.

${ }^{31}$ De tal manera que "los nombres se volvieron cosas y a las cosas señaladas con una $\mathrm{x}$ se les podía considerar como blancos de guerra" (1982:20).
} 
culminación moral; su invitación pasa por contemplar la historia como un conjunto de 'relaciones entre conjuntos de relaciones'. Y, en segundo lugar, la importancia analítica que concede al concepto de modo de producción, ya que permite "revelar las relaciones clave por medio de las cuales el trabajo social deja huella en la naturaleza" (Wolf, 1982:466) y "poner de relieve los modos cambiantes en que un modo, el capitalista, interactuó con otros modos para lograr su dominio actual" (Wolf, 1982:101). En su análisis de los procesos históricos del desarrollo mercantil y capitalista, estudia paralelamente las consecuencias sobre diferentes prácticas locales. Además, tiene en cuenta que dichos efectos no se producen sobre sujetos pasivos (gente sin historia), sino que suponen la participación de muchos pueblos que contribuyeron de forma activa a las transformaciones sufridas, siendo en cada caso una síntesis ecléctica de sus propios rasgos con las nuevas demandas del mercado. Desde esta perspectiva considera que los diferentes pueblos "no son 'antecesores contemporáneos', ni pueblos sin historia" (Wolf, 1982:465), sino agentes activos con una historia propia que debe ser entendida en un contexto global. Wolf ofrece, en definitiva, una historia (con la no-historia), para comprender los efectos de la explotación y de la dominación. Y en esa historia ocupan un lugar destacado los recursos y la manera en que concebimos nuestras relaciones con la naturaleza. De hecho, se separa, de forma tajante, del postulado estructuralista, al considerar que es por medio del trabajo social como se transforma la naturaleza ${ }^{32}$. Cada modo de producción formará una 'ecología de representaciones colectivas' y es en ellas donde es posible observar los procesos de selección y la práctica del poder ${ }^{33}$.

Ahora bien, Wolf no ha sido el único en centrar su atención en los modos de producción, desde diferentes ángulos se ha tomado dicho concepto como eje interpretativo. El argumento defendido es que, para superar el modelo dualista, es necesario atender a las relaciones establecidas entre lo cultural y lo tecnoecológico que quedan sintetizados, precisamente, en los modos de producción. En la producción es posible observar la complejidad de las respuestas culturales, más allá de considerarlas un mero proceso adaptativo, sacando a la luz los intereses, conflictos y

\footnotetext{
${ }^{32}$ Frente a quien "sostiene que la Mente sigue un curso independiente y propio, yo sostengo que la construcción de ideología no surge de la confrontación del pensar del Hombre Desnudo sobre la Naturaleza Desnuda; creo que más bien ocurre dentro del ámbito determinado de un modo de producción cuyo fin es hacer que la naturaleza se preste al uso humano" (Godelier,1982:469).

${ }^{33}$ En "Cognizing 'Cognized Models' " (1999), Wolf realiza una reflexión sobre las contribuciones de Rappaport; en él podemos ver su insistencia en la necesidad de estudiar el poder estructural desde la perspectiva de la ecología política y la historia ecológica.
} 
estrategias en juego. En Godelier encontramos una versión de este tipo de argumento, siendo su propuesta de la 'racionalidad económica' una contribución fundamental a la ecología política. Para Godelier, cada sistema económico-social determina un modo particular de explotación de los recursos. No existe una racionalidad económica única ${ }^{34}$, "cada sistema económico determina un modo específico de explotación de los recursos naturales y de empleo de la fuerza del trabajo humana, y en consecuencia determina las normas específicas del 'buen' y 'mal' uso de tales recursos y de tal fuerza, es decir, una forma específica y original de racionalidad económica intencional" (Godelier, 1989:63). Y la racionalidad intencional es "un sistema de reglas sociales, conscientemente elaboradas y aplicadas para conseguir del mejor modo un conjunto de objetivos" (Godelier, 1989:63). Por tanto, la racionalidad es la adaptación específica de cada cultura; y por adaptación entenderá la lógica material y social de explotación de los recursos y las condiciones de reproducción ${ }^{35}$. En el desarrollo de cada sistema social encontramos contradicciones (en el nivel de funcionamiento de la sociedad y en los niveles de organización de la sociedad) porque no hay un sistema totalmente integrado. Cuando se da una contradicción entre las relaciones sociales y sus condiciones de producción y reproducción (contradicciones no intencionales), los seres humanos tienen que hacerse cargo de ellas y actuar (intencionales). En la evolución de las sociedades vemos actuar ambas lógicas, intencional y no intencional, cuyo producto es la historia $^{36}$. Pero la suerte de los humanos, y su principal condición, depende de su facultad de hacerse cargo de la parte no intencional de su existencia. Sin embargo, esta especificidad humana no implica que podamos someter de forma total a la naturaleza ni dominar todas sus leyes. Para Godelier, si aceptamos esto, estamos reconociendo a la naturaleza cierta independencia y autonomía o, lo que es lo mismo, estamos reconociendo que no todo es una construcción cultural. En definitiva, los procesos de adaptación de las culturas (contradictorios e inestables) siempre implican la construcción de un sistema de representación de la naturaleza y las relaciones que se mantienen con ella dependen de ese sistema de interpretación. Para comprender

\footnotetext{
${ }^{34}$ Para Godelier es necesario tener presente que lo racional no es una búsqueda de optimización, sino más bien una respuesta de conducta intencional que permite la adaptación.

${ }^{35} \mathrm{El}$ concepto de modo de producción difiere de Wolf a Godelier; de hecho, en este último, es un término más impreciso.

36،"La intención y la acción de los hombres echa siempre sus raíces y encuentra los límites de sus efectos en las propiedades y las necesidades no intencionales de las relaciones sociales y de las condiciones de existencia. La historia, pues, no explica nada, puesto que ella misma precisa ser explicada" (Godelier, 1989:94).
} 
el desarrollo de una sociedad hay que tener en cuenta dos tipos de materialidades: una que procede de los seres humanos y otra que procede de la naturaleza. Las primeras han sido puestas en funcionamiento para actuar sobre las de las segundas. Pero no siempre la acción humana tiene todo el control sobre la naturaleza. Los efectos no intencionales nos recuerdan la imposibilidad de someterla por completo, ya que ésta guarda un grado de independencia con respecto a nosotros.

Si la racionalidad económica de Godelier, entre otras, ha sido una contribución fundamental, también es cierto que "la ecología política no tiene un corpus homogéneo, por lo que podemos encontrar reflejados en ella distintos enfoques teóricos" (Comas D’Argemir, 1998:144). El eclecticismo teórico, la multidisciplinariedad, la heterogeneidad de su metodología son, sin duda, sus rasgos más sobresalientes (Vaccaro y Beltran, 2007). Así, la ecología política tiene en común con la economía política ciertos intereses, pero tiene tantas similitudes como diferencias respecto a ella. Ambas comparten preocupaciones como las relaciones de poder que determinan los usos del medio ambiente, la historia del capitalismo y su crítica, y la desigualdad que ha generado el capitalismo a escala global. Pero la ecología política se diferencia de la economía política al subrayar los impactos del medio ambiente, las relaciones de poder que se establecen, no sólo entre clases, sino entre los seres humanos y la naturaleza (la dominación de la naturaleza) y al incorporar no sólo las complejas relaciones entre local-global, nacional-global, nacional-regional, sino también las asimetrías de poder de género, etnia, raza, etc, es decir, sobre cualquier ecoviolencia (Biersack, 1999a).

De este modo, la nueva perspectiva de la ecología política está generando múltiples investigaciones, enfatizando el papel de las prácticas y los discursos, que plantea nuevas interpretaciones sobre intereses clásicos de la antropología (como el ritual), sobre temas tradicionales de las investigaciones sociales (como los movimientos sociales) y sobre el conflicto medioambiental (como la construcción política de la naturaleza en el discursos, las prácticas y las instituciones). El trabajo de Gezon sobre los Antankarana ${ }^{37}$ (1999) es un ejemplo de cómo se puede analizar un conflicto ecológico y un ritual desde la perspectiva de la ecología política ${ }^{38}$. Desde una visión postestructuralista, se analiza cómo el simbolismo ritual es desplegado

\footnotetext{
${ }^{37}$ Los Antankarana viven en el norte de Madagascar, en una región rica en recursos de importancia nacional e internacional.
} 
discursivamente para conseguir la jurisdicción sobre los recursos, puestos en peligro por las incursiones exteriores. Así, se examinan las relaciones entre los distintos niveles políticos y las interacciones entre significado y relaciones materiales ${ }^{39}$. Para Gezon, los Antankarana realizan rituales para reclamar los recursos marinos en una tentativa de defenderse de los competidores nacionales e internacionales. Además, dichas respuestas deben entenderse en un contexto espacial y temporal más amplio; el estudio etnográfico del presente necesita atender a la historia de las relaciones interétnicas de la región (entre los Antankarana, los franceses y los Merina). El ritual, para Gezon, no es un instrumento regulador y una herramienta adaptativa, sino más bien un elemento discursivo que representa una política de oposición ${ }^{40}$. El fisehana es una herramienta política que debe entenderse en el doble contexto de la historia colonial y poscolonial de la lucha interétnica, y de la participación regional en el mercado global. La memoria histórica y la representación ritual proporcionan un marco ideológico para la negociación del control y uso del medioambiente. Gezon concluye que las relaciones ser humano/medio ambiente se forman, histórica y discursivamente, en y a través de la política y los instrumentos simbólicos.

Los estudios de Brosius (1997, 1999a, 1999b) son también un ejemplo, desde la ecología política, del análisis de las relaciones de poder y las tensiones entre lo local y lo global. Para el autor, el aumento y la rápida proliferación de los movimientos medioambientales representa una nueva forma política y un cambio fundamental en la distribución del poder ${ }^{41}$. Desde su punto de vista, el estudio de los movimientos sociales se ha centrado en las imágenes, en la contestación y en la transnacionalidad, olvidando lo que él considera crucial desde una posición foucaultiana: el hecho de que los movimientos ambientales están creando un desarrollo progresivo de vigilancia y gobierno del medio ambiente, a través de una 'institucionalización de la tierra ${ }^{42}$. Pese

\footnotetext{
${ }^{38}$ El estudio se centra en la industria de la pesca y en el papel que juega la posesión de los espíritus y la innovación ritual como instrumento de lucha para reclamar los recursos territoriales

${ }^{39}$ El contexto del análisis es el incremento, desde la década de los 70 , de la pesca del camarón en Madasgascar, lo que provocó la reacción de los Antankarana. Su líder político, reclamó la jurisdicción sobre las aguas de la costa.

40 En este sentido, se separa de las nociones funcionalistas rappaportianas criticando sus conceptos de homeostasis y equilibrio dinámico, y entendiendo que las perturbaciones son inherentes a los sistemas.

${ }^{41}$ Dicho proceso habría despertado el interés por ellos por dos motivos. En primer lugar, porque los movimientos están presentes en el contexto de investigación de los antropólogos. Y, en segundo lugar, por los nuevos intereses de la antropología (Brosius, 1999a:37). Ahora bien, indica que muy pocos antropólogos han prestado atención al campo de la institucionalización.

${ }^{42}$ Brosius sigue los trabajos de Escobar (1995b) sobre la 'institucionalización', en los que crítica el desarrollo de instituciones internacionales y sus manifestaciones locales. A través de un análisis de la construcción del tercer mundo, pone de manifiesto cómo se han creado aparatos eficaces para edificar conocimientos, desplegándose un régimen de gobierno sobre el mismo.
} 
a que la institucionalización puede ser vista, en algunos aspectos, como positiva (el propósito es la conservación medio ambiental), es necesario atender al proceso por el cual estas instituciones inscriben y naturalizan ciertos discursos, ya que al tiempo que proponen alternativas para la preservación medio ambiental, excluyen otras posibilidades, privilegian a ciertos actores y marginalizan a otros. Podemos ver esto en el proceso de desplazamiento de las iniciativas y voces indígenas por las voces nacionales e internacionales en la campaña internacional contra la destrucción de la selva y los derechos indígenas en el estado de Sarawak (al este de Malasia), en los años 90 (Brosius, 1999a). En su análisis muestra cómo los actores indígenas son desplazados por 'instituciones para la vigilancia y gobierno medioambiental local, nacional y global' (el gobierno malayo y las ONG medio ambientales del Norte ${ }^{43}$ y malayas). Los acontecimientos hicieron que el domino moral y político se deslizara hacia el dominio de la gubernamentalidad y la burocratización, a través de privilegios y exclusiones, ya que las instituciones capacitan o limitan, concretan los espacios de discurso y de praxis, definen o redefinen los espacios de acción, privilegian algunas formas de acción y limitan otras. Esta dinámica representa el desplazamiento político en el dominio del medio ambiente y debe ser leída como un proceso de gubernamentabilidad en el sentido foucaultiano ${ }^{44}$. Brosius concluye que las instituciones medio ambientales, lejos de ser liberadoras, son formas de intervención. En este sentido, Benabou (2007) en su trabajo sobre el ecoturismo en la Reserva de Nanda Devi, habla también del carácter paradójico de las ONG medioambientales al constituirse en portadoras de reivindicaciones locales pero también en figuras autoritarias. Asimismo algunos autores, como Lauer (2005) en su análisis sobre los ye'kwana del Alto Orinoco, reconocen la visión idealista y reduccionista de las ONG sobre los pueblos indígenas (visión naturalizada, podríamos añadir, que ha impregnado no sólo a las ONG) ${ }^{45}$. Y otros como Arach (2002), en su investigación sobre el movimiento originado por la represa de Yacyretá en Paraguay, apuntan que

\footnotetext{
43 "A la hora de hablar de 'medioambientalistas del Norte', imito el uso actual en el que se emplea el término 'Norte' para referirse a los países industrializados de Europa, Estados Unidos, Japón y Australia (frente al término 'Sur' que se refiere al 'Tercer Mundo')" (Brosius, 1999a:51).

44 "Utilizo el término 'gubernamentalidad' en el sentido Foucaultiano de 'racionalidad gubernamental' (Gordon, 1991). Cuando hablaba de 'gubernamentalidad', Foucault se refería, no sólo al dominio civil/político del gobierno en su acepción habitual, sino que aludía a un dominio más amplio de discursos y prácticas que crean y administran a los sujetos mediante la presencia de una serie de aparatos creadores de conocimientos" (Brosius, 1999a:51).

${ }^{45}$ Nos encontraríamos con el mito señalado por Milton (1996) de la 'sabiduría ambiental primitiva' o, como dice Descola (1998), con la 'figura filosófica del buen salvaje' que convierte, bajo la mirada del mundo industrializado, a los indígenas "en sagaces sociedades de botánicos y farmacólogos" (1998:221).
} 
los intereses y perspectivas entre las ONG y las comunidades locales divergen, aunque la acción puede converger.

En esta dirección, Kottak (1999) ha señalado que las etnoecologías locales, es decir, las percepciones sociales del medio ambiente, se encuentran hoy en día desafiadas, transformadas y reemplazadas por las propias transformaciones del mundo actual. Las migraciones, la difusión de los mass-media, las tecnologías, la industria, etc., han provocado la importación de valores y prácticas que entran a menudo en conflicto con las representaciones indígenas. Los sistemas tradicionales (sus valores, sus ideas, sus lugares) son atacados por todas partes. Pero los impactos de las fuerzas externas no son uniformes, puesto que cada comunidad tiene su propia historia y tradición; de ahí que la extensión del desarrollismo y medio ambientalismo se vea influenciada siempre por las etnoecologías nacionales, regionales y locales, y por sus poderes de adaptación y resistencia. Desde esta perspectiva, considera que la existencia de discursos homogeneizadores, como el discurso del desarrollo sostenible, está imponiendo una moral ecológica global al reemplazar las prácticas locales por normalizaciones externas. Así, Brosius (1999b) habla del aparato transnacional del desarrollo sostenible.

Pero la perspectiva de la ecología política no ha sido solamente aplicada en los contextos postcoloniales. Pese a que su impulso en la disciplina, sobre todo, en la década de los noventa, se centró en estos contextos por las propias condiciones de producción (la sustitución de las teorías desarrollistas, la degradación ecológica y el impulso de los estudios sobre el conflicto medioambiental, el aumento de las desigualdades sociales, la correspondencia entre la crisis ecológica y el empobrecimiento, las relaciones desiguales entre lo local y lo global, etcétera), durante la última década vemos la pertinencia de incorporar dicha mirada en los países industrializados. Escobar (1995a, 1996, 2000) ha puesto de manifiesto precisamente cómo el desarrollo sostenible se fundamenta en los logros de la modernidad occidental, asumiéndolos acríticamente. En dicho enunciado, la construcción histórica del complejo económico no se pone en duda, ni tampoco su concreción ni su realidad, de tal forma que la 'economización de la naturaleza' se presenta como dada (recursos, valores, productos, mercados...). Así, denuncia que el juego establecido entre economía y ecología oculta la creencia de que el sistema sólo necesita pequeños ajustes en el mercado para lograr un desarrollo ecológico, cuando en realidad lo que se 
necesita es una reestructuración integral del sistema (Santamarina, 2004). Su crítica más contundente va dirigida hacia la consideración de la naturaleza como mercancía y su propuesta pasa por la articulación de resistencias para construir nuevas estrategias productivas y para edificar una nueva representación de la Naturaleza. Para Escobar la raíz de los problemas ambientales está precisamente en la forma de organización social (1995a).

La propia crítica de Escobar al desarrollo sostenible y su consideración de que es necesario que 'antropologicemos' nuestra práctica cultural distanciándonos de la misma para comprender las estructuras históricas, ha sido continuada por numerosos antropólogos. Por ejemplo, Vaccaro (2005) ha trabajado sobre el proceso de gubernamentalidad del paisaje en el Pirineo español. La expropiación y apropiación del territorio por parte del estado moderno evidencia las relaciones entre el paisaje y la intervención política sobre el territorio y los recursos a lo largo del tiempo. En el mismo camino, se insertan los trabajos compilatorios de Fernández y Florido del Corral (2005), de Frigolé y Roigé (2006), de Vaccaro y Beltran (2007) o de Selmi y Hirtzel (2007) que introducen la perspectiva de la ecología política en el análisis del paisaje y los parques naturales estudiando la relación entre los cambios ecológicos, los procesos políticos y los económicos. Mi propio trabajo sobre la institucionalización y normalización de lo ecológico (Santamarina, 2006a) o sobre el análisis de las prácticas y narraciones en la conformación de los espacios naturales y de los discursos hegemónicos (Santamarina, 2005; 2006b) se sitúan en esta línea.

En definitiva, la perspectiva de la ecología política se nos presenta hoy como un campo de análisis fructífero, que permite destapar los mecanismos implícitos de las relaciones de poder. El desarrollo de la ecología política supone un nuevo esfuerzo en la comprensión de los vínculos ideológicos que subyacen a cualquier representación ecológica. La incorporación en los análisis de las relaciones entre lo local y lo global; el énfasis en mostrar que las prácticas y los discursos, como productos históricos y culturales, condicionan nuestras relaciones con el entorno; el hecho de sacar a la luz que hay distintas lógicas materiales y sociales que determinan nuestra relación con el medio y que existen otras formas posibles de configurar los vínculos naturaleza/cultura, son aportaciones que nos invitan a una nueva consideración sobre lo ecológico más allá de los determinismos tradicionales de nuestra disciplina. 


\section{Recapitulación: hacia una nueva antropología comprometida}

La antropología, igual que ha ocurrido con el desarrollo de otras ciencias, ha sido presa de sus propias representaciones conduciendo, en muchos casos, a una reafirmación de los modelos culturales occidentales como hegemónicos de los sistemas cognitivos. De hecho, es sorprendente que, hasta hace relativamente poco, la disciplina no haya logrado deconstruir las categorías de naturaleza y cultura, sobre todo si se tiene en cuenta que dichos conceptos son centrales en una serie de oposiciones clave del pensamiento occidental que los antropólogos han conseguido desmantelar con cierta solvencia, tales como mente-cuerpo, sujeto-objeto, etc. (Descola y Pálsson, 1996). Ahora bien, después de haber puesto en tela de juicio dicha dicotomía, la disciplina ha abierto un nuevo campo de análisis especialmente interesante en el contexto actual de una degradación medioambiental sin precedentes y sin límites. Desde nuestra consideración, las perspectivas de la ecología simbólica y de la ecología política, son las que mejor permiten entablar un diálogo sobre cómo nuestros procesos culturales han construido una imagen muy particular del mundo natural y sobre cómo se está elaborando la compleja categoría de medio ambiente. Desde nuestro punto de vista, el medio ambiente se nos presenta como una categoría política producida desde instancias tecno-científicas, que desplaza el mundo de lo natural en favor de un único mundo cultural, al reducir la naturaleza a una mera mercancía (materia, producto, recurso). Y, al hacerlo, parece haber obviado las múltiples dimensiones, así como los límites que en sí misma contiene.

En este sentido, se hace ineludible comprender los mecanismos de poder que subyacen a nuestra práctica cultural y recordar que la naturaleza y la cultura son realidades construidas por procesos culturales a través de prácticas, discursos e instituciones. La estrategia de reducción para el control y la destrucción de la(s) naturaleza(s) y de la(s) cultura(s) se ha basado en una edificación objetiva de estas realidades como objetos transaccionales y como sujetos de apropiación lícita. La legitimación sobre el(los) otro(s) ha pasado por estrategias de subordinación que incluían su confinamiento como paso necesario para su colonización. Tras la práctica de naturalizar a las culturas y a los diversos otros (mujeres, razas, clases...) y tras la práctica de culturizar a la naturaleza (convertida, de igual modo, en otro) 
encontramos un aparato análogo que permite imponer una visión normal y normalizada de nuestras relaciones con el mundo a partir de la comparación, la diferencia, la exclusión y la jerarquización. Estos dispositivos tradicionales han domesticado y, en muchos casos, destruido (en lo real y en lo simbólico) a todos estos Otros bajo distintos discursos disfrazados de paternalismo autoritario ${ }^{46}$. Todo esto se ha llevado a cabo desde relaciones de poder asimétricas, que se sustentan en aras del desarrollo, la evolución, el bienestar, la protección... y que siguen fabricando nuevos modelos de interpretación, las cuales, lejos de romper con las viejas fórmulas opresivas, las reafirman (globalización) (Petras y Veltmeyer, 2002). El resultado de dicho proceso ha sido la constitución de una cultura (bajo la capa de lo occidental), caracterizada por su cualidad de ser global, universal y homogénea, que acosa a los conocimientos locales y reduce a la naturaleza a su dominio. En suma, lo que tratamos de poner de manifiesto es que, en la construcción de la naturaleza ha jugado un papel destacado nuestra manera de concebir la cultura y los otros. $Y$ que dicha concepción responde a una misma lógica de reducción y normalización que han sufrido de forma paralela la cultura, los otros y la naturaleza. Al margen de otro tipo de consideraciones (de la destrucción de modos de vida, de la desposesión de masas ingentes, del asesinato, del ecocidio,...), el gran éxito del progreso es un mundo cultural que impone a destajo sus productos, sus objetividades y sus autenticidades.

En definitiva, podemos decir que, en un sistema donde se nos imponen visiones hegemónicas y discursos ecológicos globalizados, basados en una racionalidad político-económica que se pretende única, se hace necesario un análisis crítico para descifrar las claves de nuestra práctica cultural y para poner en práctica todo el conocimiento local aprendido, que permita sacar a la luz otros discursos practicables posibles desde lógicas marginales. Tal y como ha puesto de manifiesto Escobar, "si es cierto que siempre hay formas de posdesarrollo, no capitalismo y 'otras naturalezas' en construcción, entonces, hay esperanza de que se puedan llegar a constituir nuevas bases para la existencia y rearticulaciones significativas de la subjetividad y de la alteridad en sus dimensiones económica,

\footnotetext{
46 Las culturas a través de las distintas formas de colonialismo y de dependencia (bajo manifestaciones ideológicas, políticas, económicas, religiosas, científicas...), la naturaleza a través del capitalismo y de la explotación de los recursos (bajo manifestaciones ideológicas, políticas, económicas, religiosas, científicas...), y las mujeres, por poner un ejemplo más, a través del patriarcado y del androcentrismo (bajo manifestaciones ideológicas, políticas, económicas, religiosas, científicas...).
} 
cultural y ecológica" (2000:209). Así el reto de la nueva antropología ecológica o medio ambiental pasa porque la práctica antropológica "pueda usarse como un instrumento para la reflexión crítica y como una herramienta para la liberación humana" (Scheper-Hughes, 1997:39). Y como nos sugiere Ingold, "el último objetivo de la investigación medio ambiental en antropología social" debería desestabilizar la jerarquía de poder y control, siendo sus recursos "no tanto técnicos y metodológicos como políticos y epistemológicos" (Ingold, 2000: 222). Denunciar los desequilibrios y desigualdades de nuestro mundo y recuperar otras maneras posibles de construir nuevos escenarios para el presente presupone un esfuerzo y compromiso colectivo por redefinir nuestro mundo.

\section{Bibliografía}

Arach, Omar (2002). Ambientalismo, desarrollo y transnacionalidad: las proestas sociales en torno a la represa de Yacyretá. Cuadernos para el Debate, 16:5-46.

Arhem, Kaj (1996). The cosmic food web: human-nature relatedness in the Northwest Amazon. En Nature and Society. Anthropological perspectives. Philippe Descola. y Gísli Pálsson, eds. Londres: Routledge.

Benabou, Sarah (2007). Les dimensions socio-culturelles de la mise en écotourisme. Le cas de la réserve de biosphère Nanda Devi. Cahiers d'antropologie sociale, 3:109-123.

Biersack, Aletta (1999a). From the 'New Ecology' to the New Ecologies. American Anthropologist, 101(1): 2-18.

Biersack, Aletta (1999b). The Mount Kare Python and His Gold: Totemism and Ecology in the Papua New Guinea Highlands. American Anthropologist, 101(1):68-87.

Brosius Peter (1997). Endangered Forests, Endangered People. Environmentalist Representations of Indigenous Knowledge. Human Ecology, 25: 47-69

Brosius, Peter (1999a). Green Dots, Pink Hearts: Displacing Politics from the Malaysian Rain Forest. American Anthropologist 101(1): 36-57.

Brosius, Peter (1999b). Anthropological engagements with enviromentalism. Current Anthropology, 40(5):277-309.

Cassirer, Ernst (1965). Antropología filosófica: introducción a una filosofía de la cultura. México: FCE. Comas d'Argemir, Dolors (1998). Antropología económica. Barcelona: Ariel.

Clifford, James y Marcus, George (1991). Retóricas de la Antropología. Madrid: Júcar.

Descola, Philippe (1986). La Nature Domestiqué. Symbolisme et praxis dans l'écologie des Achuar. Paris: Maison des sciences de l'homme.

Descola, Philippe (1993). Les lances du crépuscule. Relations Jivaros, Haute-Amazonie. Paris: Plon. 
Descola, Philippe (1996): "Constructing natures: symbolic ecology and social practice". En Nature and Society. Anthropological perspectives. Philippe Descola. y Gísli Pálsson, eds. Londres: Routledge.

Descola, Philippe (1998). Las comologías de los indios de la Amazonía. Zainak, 17:219-227.

Descola, Philippe (1999). Écologiques. En La production du social. Philippe Descola, Jacques Hamel, y Pierre Lemonnier, eds. Paris: Fayard.

Descola, Philippe (2003). Antropología de la naturaleza. Lima: Instituto Francés de Estudios Andinos. Lluvia Editores.

Descola, Philippe y Pálsson, Gísli (ed.)(1996). Nature and Society. Anthropological perspectives. Londres: Routledge.

Douglas, Mary (1973). Sobre la naturaleza de las cosas (la evidencia). Madrid: Anagrama.

Douglas, Mary (1988). Símbolos naturales. Madrid: Alianza Universidad.

Ellen, Roy (1996). The cognitive geometry of nature: a contextual approach. En Nature and Society. Anthropological perspectives. Philippe Descola. y Gísli Pálsson, eds. Londres: Routledge.

Escobar, Arturo (1995a) El desarrollo sostenible: Diálogo de discursos. Ecología Política, 9:7-27.

Escobar, A., (1995b): The Making and Unmaking of the third world. Princeton University Press. Estados Unidos.

Escobar, Arturo (1996). Constructing Nature. Elements for a postructural political ecology. En Liberation ecologies. Peet, R., y Watts, M., ed. Londres: Routledge.

Escobar, Arturo (2000). El lugar de la naturaleza y la naturaleza del lugar. En Antropología del desarrollo. Andreu Viola, comp.Barcelona: Paidós.

Fernández, Pascual y Florido del Corral, David (2005).¿Protegiendo los recursos? Áreas protegidas, poblaciones locales y sostenibilidad. Sevilla: Fundación Monte.

Foucault, Michel [1966](1997). Las palabras y las cosas. Madrid: SXXI.

Foucault, Michel [1975](1994). Vigilar y Castigar. Madrid: SXXI.

Foucault, Michel [1978](1991). La gubernamentalidad. En Espacios de poder. Castel, Robert y otros. Madrid:Piqueta.

Frigolé, Joan y Roigé, Xavier (2006). Globalización y localidad: perspectiva etnográfica. Barcelona: Publicacions i Edicions UB.

Gezon, Lisa (1999). Of Shrimps and Spirit Possession: Toward a Political Ecology of Resource Management in Northern Madagascar". American Anthropologist, 101(1):58-67.

Godelier, Maurice (1989). Lo ideal y lo material. Madrid: Taurus.

Goledier, Maurice (1998). El enigma del don. Barcelona: Paidós.

Haraway, Donna (1995). Ciencia, cyborgs y mujeres. La reinvención de la naturaleza. Madrid: Cátedra.

Haraway, Donna (1999). Las promesas de los monstruos: una política regeneradora para los otros inapropiados/bles. Política y Sociedad, 30:121-164.

Harris, Marvin (1982). El materialismo cultural. Madrid: Alianza.

Harris, Marvin [1968](1987). El desarrollo de la teoría antropológica. Una historia de las teorías de la cultura. Madrid: SXXI. 
Harris, Marvin [1974](1989). Vacas, cerdos, guerras y brujas. Madrid: Alianza.

Harris, Marvin [1985](1997). Bueno para comer. Madrid: Alianza.

Holland-Cunz, Barbara (1996): Ecofeminismos. Valencia: Cátedra

Hornborg, Alf (1996). Ecology as semiotics: outlines of a contextualist paradigm for human ecology". En Nature and Society. Anthropological perspectives. Philippe Descola. y Gísli Pálsson, eds. Londres: Routledge.

Hornborg, Alf y Pálsson, Gísli (2000). Negotiating Nature: Culture, Power, and Environmental Argument. Lund: Lund University Press.

Howell, Signe (1996). Nature in culture or culture in nature? Chewong ideas of 'humans' and the other species. En Nature and Society. Anthropological perspectives. Philippe Descola. y Gísli Pálsson, eds. Londres: Routledge.

Hviding, Edvard (1996). Nature, culture, magic, science: on meta-languages for comparison in cultural ecology. En Nature and Society. Anthropological perspectives. Philippe Descola. y Gísli Pálsson, eds. Londres: Routledge.

Ingold, Tim (2000). Concluding Commentary. En Negotiating Nature: Culture, Power, and Environmental Argument, Alf Hornborg y Gísli Pálsson (eds). Lund: Lund University Press.

Kottak, Conrad (1999). The New Ecological Anthropology. American Anthropologist ,101(1):23-35.

Kroeber, Alfred [1917](1975). Lo superorgánico. En El concepto de cultura: textos fundamentales. Joel Kahn. Barcelona: Anagrama.

Kroeber, Alfred [1952](1993). Los determinantes de la cultura. En Antropología. Lecturas. Paul Bohannan y Mark Glazer, eds. México: McGraw-Hill.

Latour, Bruno (1993). Nunca hemos sido modernos. Ensayo de antropología simétrica. Madrid: Debate.

Latour, Bruno (2001). La esperanza de Pandora. Ensayos sobre la realidad de los estudios de la ciencia. Barcelona: Gedisa.

Lauer, Matthew (2005). Lideres políticos indígenas en Amazonia: política y auto-representación. AIBR. Revista de Antropología Iberoamericana, 41:1-20.

Lévi-Strauss, Claude [1949](1981). Las estructuras elementales de parentesco. Barcelona: Paidós.

Lévi-Strauss, Claude [1962](1988). El pensamiento salvaje. México: F.C.E.

Lévi-Strauss, Claude [1962](1997). El totemismo en la actualidad. Madrid: F.C.E.

Lévi-Strauss, Claude [1978](1987). Mito y significado. Madrid: Alianza.

Luque Baena, Enrique (1990). Del conocimiento antropológico. Madrid: CIS.

MacCormack, Carol y Strathern, Marilyn (1980). Nature, Culture and Gener. Nueva York: Cambridge University.

Malinowski, Bronislaw [1944](1984). Una teoría científica de la cultura. Madrid: Sarpe.

Mies, María y Shiva, Vandana (1997). Ecofeminismo. Teoría, crítica y perspectivas. Barcelona: Icaria.

Mies, María y Shiva, Vandana (1998). La praxis del ecofeminismo. Biotecnología, consumo, reproducción. Barcelona: Icaria.

Milton, Kay (1996). Environmentalism and Cultural Theory. Londres: Routdge. 
Milton, Kay (2001a). Ecologías: antropología, cultura y entorno. Revista Internacional de Ciencias Sociales, 154:86-115.

Milton, Kay (2001b). Loving Nature. Towards an ecology of emotion. Londres: Routdge.

Molyneux, Maxina y Steinberg, Lynn (1994): El ecofeminismo de Shiva y Mies: ¿Regreso al futuro?. Ecología Política, 8:13-25.

Nothnagel, Detlev (1996). The reproduction of nature in contemporary high-energy physics. En Nature and Society. Anthropological perspectives. Philippe Descola. y Gísli Pálsson, eds. Londres: Routledge.

O'Connor, James (1992). Las dos contradicciones del capitalismo. Ecología Política 3:111.

O'Connor, Martin (1994). El mercadeo de la naturaleza. Sobre los infortunios de la naturaleza capitalista. Ecología Política, 7: 15-35

Orlove, Benjamin (1980). Ecological Anthropology. Annual Reviews Anthropology, 9:235-273.

Papagaroufali, Eleni (1996). Xenotransplantation and transgenesis: im-moral stories abaot humananimal relations in the West. En Nature and Society. Anthropological perspectives. Philippe Descola. y Gísli Pálsson, eds. Londres: Routledge.

Petras, James y Veltmeyer, Henry (2002). El imperialismo en el siglo XXI. La globalización desenmascarada. Madrid: Popular.

Rappaport, Roy (1975). Naturaleza, cultura y antropología ecológica. En Hombre, cultura y sociedad. Shapiro, ed. México: FCE.

Rappaport, Roy (1987). Cerdos para los antepasados. El ritual en la ecología de un pueblo de Nueva Guinea. Madrid: SXXI.

Rappaport, Roy (1999). Ritual y religión en la formación de la humanidad. Madrid: Cambridge.

Rival, Laura (1996). Blowpipes and spears: the social significance of Huaorani technological choices. En Nature and Society. Anthropological perspectives. Philippe Descola. y Gísli Pálsson, eds. Londres: Routledge.

Sahlins, Marshall [1976](1997) Cultura y Razón Práctica. Barcelona: Gedisa.

Salleh, Ariel (1994). Naturaleza, mujer, trabajo, capital: la más profunda contradicción. Ecología Política, 7: 35-47.

Salleh, Ariel (1995) Ecosocialismo-ecofeminismo. Ecología Política, 8:89-93.

Santamarina, Beatriz (2004). Desarrollo sostenible. Una suerte de comodín. Arxius de Ciencias Sociales, 11: 201-215

Santamarina, Beatriz. (2005). La patrimonialización de la naturaleza: figuras y discursos. En ¿Protegiendo los recursos? Áreas protegidas, poblaciones locales y sostenibilidad. Pascual Fernández y David Florido del Corral, eds. Sevilla: Fundación Monte.

Santamarina, Beatriz (2006a). Ecología y poder. El discurso medioambiental como mercancía. Madrid: Libros de la Catarata.

Santamarina, Beatriz (2006b) Del desarrollo sostenible a la sostenibilidad del desarrollo. Un análisis sobre las estrategias políticas del desarrollo sostenible. En Territorializaiçao, Meio Ambiente e Desenvolvimiento no Brasil e na Espanha. José María Valcuente del Rio, J. y Lais Cardia. Río: Editorial Universidade Federal do Acre. 
Santamarina, Beatriz (2007). Mezcla y disolución: Priones y clones. Revista Inserticios de Sociología, 1(1): 139-146.

Schepper-Hughes, Nancy (1997). La muerte sin Ilanto. Violencia y vida cotidiana en Brasil. Barcelona: Ariel.

Selmi, Adel y Hirtzel, Vincent (2007). Gouverner la nature. Cahiers d'antropologie sociale. Paris: Herne.

Steward, Julian [1955](1993). El concepto y el método de la ecología cultural. En Antropología. Lecturas. Paul Bohannan y Mark Glazer, eds. México: McGraw-Hill.

Turner, Victor [1967](1980). La selva de los símbolos. Madrid: SXXI.

Turner, Victor [1968](1990). El proceso ritual. Estructura y antiestructura. Madrid: Taurus.

Vaccaro, Ismael (2005). Property Mosaic and State-making: Governmentality, Expropriation and Conservation in the Pyrenees. Journal of Ecological Anthropology, 9: 4-19.

Vaccaro, Ismael y Beltran, Orial (2007). Ecología política de los Pirineos. Estado, Historia y Paisaje. Barcelona: Garsineu Edicions.

Valdés, María y Valdés, Ramón (1996). Ecología y cultura. En Ensayos de antropología cultural. Joan Prat y Angel Martínez (ed). Barcelona: Ariel.

White, Leslie [1949](1993a). El símbolo: el origen y la base del comportamiento. En Antropología. Lecturas. Paul Bohannan y Mark Glazer, eds. México: McGraw-Hill.

White, Leslie [1949](1993b). La energía y la evolución de la cultura. En Antropología. Lecturas. Paul Bohannan y Mark Glazer, eds. México: McGraw-Hill.

White, Leslie [1959](1975). El concepto de cultura En El concepto de cultura: textos fundamentales. Joel Kahn. Barcelona: Anagrama.

Wolf, Eric (1982): Europa y la gente sin historia. México: FCE.

Wolf, Eric (1999). Cognizing ‘Cognized Models. American Anthropologist, 101(1): $19-22$. 